\title{
SUBSTITUIÇÃO ISOMÓRFICA EM ÓXIDOS DE FERRO DE LATOSSOLOS DA AMAZŌNIA E SUAS IMPLICAÇÕES NA SORÇÃO DE FÓSFORO
}

\author{
MARIA REGINA FREIRE MÖLLER \\ Quimico Industrial
}

Orientador: Prof. Dr. TOSHIAKI KINJO

\begin{abstract}
Tese apresentada à Escola Superior de Agricultura "Luiz de Queiroz", da Universidade de São Paulo, para obtenção do título de Doutor em Agronomia, Area de Concentração: Solos e Nutrição de Plantas.
\end{abstract}

P I R A C I C A B A

Estado de são Paulo - Brasil

Maio - 1991 
Ficha catalográfica preparada pela seção de Livros da Divisão de Biblioteca e Documentação - PCAP/USP

M"̈Iler, Maria Regina Freire

M726a Substituição iscmófica en óxidos de ferro de Latossolos da Amazônia e suas implicaçōes na sorçao de fósforo. Piracicaba, 1991. $70 \mathrm{p}$.

Tese - ESALQ

Bibliografia.

1. Fósforo em solo - Sorção - Amazōnia 2. Exido de ferro em solo - Substituição isomórfica - Amazōnia 3. Solo - Mineralogia - Amazōnia 4. Solo - Química Amazōnia I. Escola Superior de Agricultura Luiz de Queiroz, Piracicaba. 


\section{SUBSTITUIÇÃOO ISOMÓRFICA EM ÓXIDOS DE FERRO DE LATOSSOLOS DA AMAZŌNIA E SUAS IMPLICAÇÕES NA SORÇÃO DE FÓSFORO}

MARIA REGINA FREIRE MÖLLER

Aprovada em: 02 de Agosto de 1991

Comissão julgadora:

Prof. Dr. Toshiaki Kinjo

ESALQ/USP

Prof. Dr. Arary Marconi

ESALQ/USP

Prof. Dr. Jorge KiehI

ESALQ/USP

Dr. Tarcisio Ewerton Rodrigues

SNLCS / EMBRAPA

Dr. Humberto Gonçalves dos Santos

SNLCS / EMBRAPA

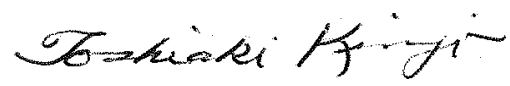

Prof. Dr. TOSHIAKI KINJO

Orientador 
LISTA DE FIGURAS $\ldots \ldots \ldots \ldots \ldots \ldots \ldots \ldots \ldots \ldots \ldots$

LISTA DE QUADROS ............................ vi

RESUMO $\ldots \ldots \ldots \ldots \ldots \ldots \ldots \ldots \ldots \ldots \ldots \ldots \ldots \ldots \ldots . \ldots \ldots \ldots$

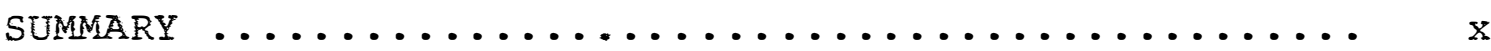

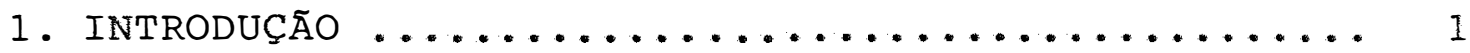

2. REVISÃO DE LITERATURA ....................... 3

2.1. Composição mineralógica da fração argila dos solos da Região Amazōnica ................. 3

2.2. Caulinitas dos solos da Região Amazōnica .... 6

2.3. Oxidos de ferro das argilas dos solos ...... 7

2.4 . Sorção de fósforo ................... 12

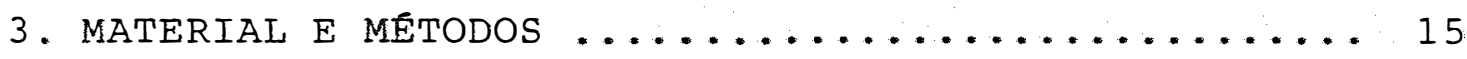

3.1. Separação de argila ................... 15

3.2. Concnetração dos óxidos de ferro .......... 18

3.3. Métodos químicos da avaliação da substituição isomórfica do alumínio .................... 18

3.4. Determinação da área superficial específica . 20

3.5. Testes de dissolução dos óxidos de ferro .... 20

3.6. Difratometriade raios $x \ldots \ldots \ldots \ldots \ldots \ldots \ldots$ 
página

3.7. Medidas da posição das linhas de difração de raios X e cálculo da substituição isomórfica. 21

3.8. Cálculo da dimensão média dos cristais (MCD) $\cdot 22$

3.9. Sorção de fósforo .................. 23

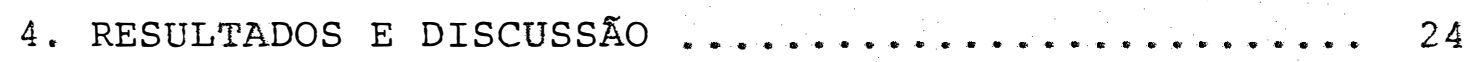

4.1. Identificação dos minerais de ferro na fração

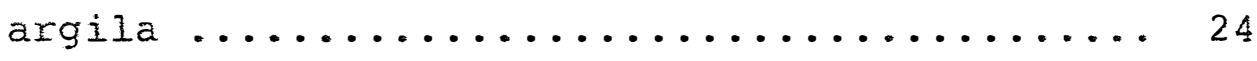

4.2. Quantificação dos óxidos de ferro na TFSA e na fração argila, substiuição isomórfica ava liada por métodos químicos $\ldots \ldots \ldots \ldots \ldots \ldots 28$

4.3. Dissolução de óxidos de ferro; fração de óxi dos de ferro com diferentes substituições iso mórficas ......................... 38

4.4. Sorção de fósfofo $\ldots \ldots \ldots \ldots \ldots \ldots \ldots \ldots \ldots$. 48

5. CONCLUSÕES $\ldots \ldots \ldots \ldots \ldots \ldots \ldots \ldots \ldots \ldots \ldots \ldots \ldots \ldots$

REFERENCIAS BIBLIOGRÄICAS $\ldots \ldots \ldots \ldots \ldots \ldots \ldots \ldots \ldots \ldots \ldots$

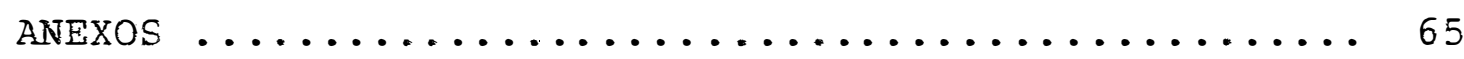




\section{LISTA DE FIGURAS}

página

FIGURA I - Difratogramas de óxidos de ferro separados das argilas dos solos $\mathrm{LR}_{12}, \mathrm{LV}_{8}$ e $\mathrm{LA}_{2} \ldots 25$

FIGURA 2 - Difratogramas de óxidos de ferro separados da fração argila da amostra $L_{2} \ldots \ldots \ldots 26$

FIGURA 3 - Difratogramas das argilas do solo LA 2 an tes e após o tratamento CBD a quente ..... 31

FIGURA 4 - Difratograma da argila do solo $\mathrm{LA}_{4} \ldots \ldots .43$

FIGURA 5 - Curvas de dissolução dos óxidos de ferro a frio e substituição isomórfica superior a 33 moles de aluminio por cento ........ 44

FIGURA 6 - Curvas de sorção de fósforo nas argilas dos solos $\mathrm{LA}_{2}, \mathrm{LA}_{4}$ e $\mathrm{LV}_{8} \ldots \ldots \ldots \ldots \ldots \ldots$ 
LISTA DE QUADROS

página

QUADRO 1 - Profundidade dos horizontes, litologia, clima e localização dos solos ......... 16

QUADRO 2 - Algumas propriedades dos solos estudados.

QUADRO 3 - Ferro e alumínio extraídos, substituição isomórfica de alumínio na TFSA e argila pelo método de MEHRA \& JACKSON (1959) e

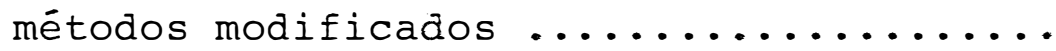

QUADRO 4 - Medidas de MCD da goethita (110) na amos tra LA 2 antes e após 24 e 48 horas de ex

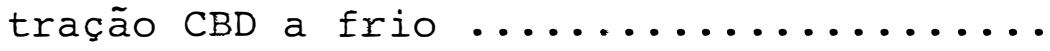

QUADRO 5 - Correlação simples entre a porcentagem de FE extraído das argilas dos solos pelo mé todo MEHRA \& JACKSON (I) e pelos métodos modificados (II, III, IV e V) $\ldots \ldots \ldots \ldots$

QUADRO 6 - Correlação simples entre a porcentagem de Al extraído dos óxidos das frações argi las dos solos pelo método MEHRA \& JACKSON (I) e pelos métodos dos Modificados (II e III) 
QUADRO 7 - Correlação simples entre as substituições isomórficas de ferro por aluminio, expres

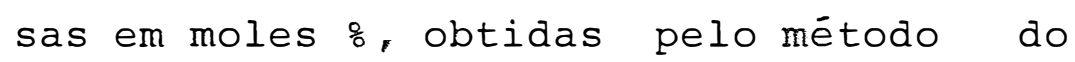
MEHRA \& JACKSON (I) e pelos métodos modi

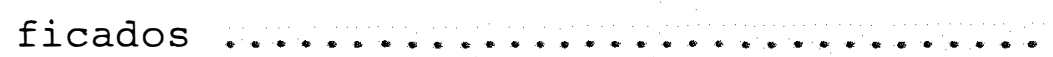

QUADRO 8 - Alumínio extraído da fração argila dos so los por três ataques sucessivos de citra to-bicarbonato, à quente ..............

QUADRO 9 - Porcentagem de ferro dissolvido, moles por cento de alumínio na estrutura dos ó xidos avaliados a cada 12 horas de disso lução e porcentagem de óxidos com Al es trutural $33 \% \ldots \ldots \ldots \ldots \ldots \ldots \ldots$

QUADRO 10 - Angulo $2 \theta$ observado e corrigido pelo com putador por comparação dos picos com o pa drão interno de silício, na amostra de ó

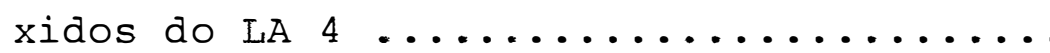

QUADRO 11 - Dimensão média dos cristais e substitui ções isomórficas das amostras de óxidos a valiadas por difratometria de raios $\mathrm{x} \ldots 46$

QUADRO 12 - Caracteristicas das caulinitas e dos óxi

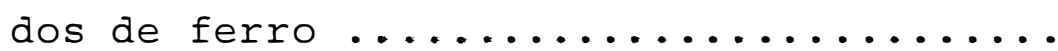




\section{SUBSTITUICÃO ISOMÓRFICA EM ÓXIDOS DE FERRO DE LATOSSOLOS DA AMAZŌNIA E SUAS IMPLICAÇŌES NA SORÇÃO DE FÓSFORO}

Autor: MARIA REGINA FREIRE MOLLER Orientador: Prof. Dr. TOSHIAKI KINJO

RESUMO

Análises mineralógicas e químicas de óxidos de ferro e caulinitas, além da avaliação da sorção de fósfó ro, foram efetuadas na fração argila de sete latossolos da Região Amazōnica com a finalidade de estabelecer relaçōes en tre as características dos óxidos, sobretudo da substituição isomórfica e a sorção de fósforo.

As goethitas da mistura de óxidos apresenta ram alta substituição isomórfica de ferro por alumínio. Essa alta substituição, que mostrou dificultar a dissolução des tes minerais pelo citrato-ditionito-bicarbonato, superenden temente não se reflete na diminuição do tamanho dos cris tais, que alcançaram valores de até $102 \mathrm{~nm}$. Uma porção da mis tura de goethitas (até 10\%), alcançou substituição isomórfí ca superior a 33 moles por cento, valor máximo comumente en contrado nesse mineral.

As hematitas não puderam ser avaliadas por di fratometria de raios $\mathrm{x}$ devido à pequena intensidade e grande 
dispersão dos picos, além da presença de rutilo.

$$
\text { Não foram encontradas correlações entre }
$$

substituição isomórfica do ferro por alumínio nas goethitas e a sorção de fósforo, mas sim, entre estas e a ărea superfi cial específica e a dimensão média do cristal. 


\section{THE IRON OXIDES ISOMORPHIC SUBSTITUTION \\ FROM AMAZON LATOSOLS AND PHOSPHORUS \\ SORPTION IMPLICATIONS}

Author: MARIA REGINA FREIRE MÖLLER

Adviser: Prof. Dr. TOSHIAKI KINJO

SUMMARY

Chemical and mineralogical analysis of iron

oxides and kaolinite, other phosphorus sorption tests were made in the clay fraction of seven amazon latosols in view of establish relationships between oxides characteristics and phosphorus sorption.

The goethite of iron mixture showed a high isomorphic substitution of aluminum by iron. This high subs titution, which showed to increase be "the difficulty of dissolution of those minerals by citrate-dithionite-bicarbo nate, surprisingly did not reflect the size reduction of the cristal, which values were as high as $102 \mathrm{~nm}$. Part of the mixture of goethites (up to 10\%), showed a level of isomorphic substitutions higher than 33 moles percent, maximum values normaly found in soils.

The hematites could not be studied by $x$-ray diffractions due to the short intensity and high despertion of the peaks and to the presence of rutile. 
No correlations were found between the isomor phic substitution of aluminum by iron in goethites and the phosphorus sorption, but a correlation existed between the sorption of phosphorus and the specific surface area or the mean crystaline dimention. 


\section{INTRODUÇÃO}

Os Latossolos têm sido solos estensivamente $\underline{u}$ tilizados na agricultura da Região Amazōnica. Estes solos tēm, como uma das características, a sorção do fósforo apli cado, notadamente devido à presença de óxidos de ferro, mine rais bastante efetivos nesse fenōmeno.

No estudo dos óxidos de ferro, é comum a uti lização de minerais padrões recém precipitados no laborató rio, com os quais são feitas observações relativas à sua gê nese e comportamento físićo e químico, as quais posteriormen te serão extrapoladas para os solos. Embora este procedimen to tenha nitidas vantagens, sobretudo pela possibilidade do estudo de espécies mineralógicas puras, algumas vezes ocorem discrepâncias de comportamento que dificultam a explicação de certos fenômenos observados nos solos. O desvio de compor tamento entre os minerais sintetizados em laboratório e aque les dos solos, provavelmente possa ser a explicação para es te fato.

A utilização de minerais naturais (misturas de óxidos de ferro extraídas dos solos), tem sido pouco uㅡ sual porque existem dificuldades analiticas tanto na concen 
tração dos óxidos de ferro, como na sua dissolução, procedi mentos indispensáveis para a realização de certos estudos es pecíficos desta fração coloidal, sobret. ao seu comportamento físico-químico. Alm desses problemas a naliticos, alguns solos, notadamente aqueles onde predominam as goethitas, têm baixo teor de $\mathrm{Fe}_{2} \mathrm{O}_{3}$, o que vem desencora jando as pesquisas com óxidos extraídos dos solos.

Uma possibilidade no estudo do comportamento dos óxidos de ferro seria a utilização de solos cuja fração silicatada fosse a mais uniforme possivel, assim o estudo de determinadas caracteristicas dos óxidos de ferro que tem in fluéncia direta no seu comportamento no solo seria possível.

Dentre estas caracteristicas, podem-se citar a substituição isomórfica do ferro pelo aluminio nos óxidos, - tamanho das particulas e seu grau de estabilidade e reati vidade, uma vez que as reações fisico-quimicas dos óxidos o correm nas superficies quebradas dos mesmos. Com o auxilio desses parâmetros provavelmente poderão ser traçados parale los entre a mineralogia dos óxidos de ferro e a sorção do fósforo adicionado aos solos.

Neste trabalho, utilizando-se Latossolos da Região Amazōnica, buscou-se avaliar, após um estudo mineraló gico bastante detalhado, qual a influência da substituição í somórfica do ferro dos óxidos por alumínio, na sorção de fós foro. 


\section{REVISÃO DE IITERATURA}

2.1. Composição mineralógica da fração argila dos solos da Região Amazōnica

Os solos bem desenvolvidos e drenados da Re gião Amazônica brasileira, representados pelos Latossolos, Podzölicos e Terra Roxa Estruturada, tēm suas frações coloi dais inorgānicas, o reflexo do intenso intemperismo químico a que estão submetidos. Seus minerais primários perdem significativamente os metais alcalinos, alcalinos-terrosos e o silício, ocasionando um enriquecimento relativo de ferro e aluminio nas suas fracões coloidais inorgānicas. Os proces sos genéticos dos seus minerais secundários são portanto, processos de ảegradação, excessão feita aos minerais chamą dos de 2:1:1 ou 2:2. Esses últimos, encontrados em pequenas. quantidades nos solos acima citados, são oriundos da agrada ção das vermiculitas e montmorilonitas, minerais secundários instáveis nas condições ambientais desses solos mas que, com a inclusão de polímeros de alumínio entre suas camadas, se estabilizam (CARSTEA, 1968). Trabalhos realizados com solos da Região Amazōnica brasileira (CHIBA, 1970; IWASA, 1976 e 
KITAGAWA \& MOLLER, 1979) têm mostrado este comportamento, em bora algumas vezes, nesses solos ainda se encontrem tracos de minerais primários.

Os Latossolos apresentam nitida domināncia de argilo-minerais $1: I$ em sua fração coloidal inorgãnica, a e xemplo do que tem sido observado em outras áreas tropicais (TOWSAND \& READ, 1971 e ALWIS\& PLUTH, 1976). Como minerais acessórios ou traços, tem sido freqllentemente encontrados gibbsita, hematitas, goethitas, micas, quartzo, minerais 2:I ou 2:2 e até mesmo feldspatos (KITAGAWA \& MOLLER, 1979).

Os Podzólicos apresentam um quadro mineralógi co bastante semeIhante aos Latossolos, enquanto nas Terras Roxas Estruturadas por vezes encontram-se hematitas com teo res comparáveis aos das caulinitas. E interessante notar, no entanto, que nestas classes de solos, apesar do intenso in temperismo químico sofrido, é muito provável que ainda ocor ram níveis de silicio relativamente altos, uma vez que não se conhece na região fração argila dominantemente gibbsitica como no Brasil Central. O valor máximo de gibbsita determina do, que suporta menos de 1 ppm de silício na solução (KITTRICK, 1969) foi de $22 \%$ numa Terra Roxa Estruturada de Mato Grosso, região já próxima ao Cerrado brasileiro.

Contrastando com esses solos bem desenvolvi dos e drenados, e ocupando menor área, os solos formados pe la deposição de detritos trazidos pelos rios ou originados sob condições permanentes ou periódicas de hidromorfismo, os 
Solos Gleis, as Lateritas Hidromórficas e os Solos Aluviais, apresentam uma mineralogia bastante variada, condicionada ao próprio material depositado e ao hidromorfismo. Neles, as do mināncias mineralógicas são tão distintas como filossilica tos 1:1 ou misturas destes com micas e interestratificados montmorilonitas/vermiculitas, até predomināncias nitidas de minerais 2:1, como mostram KITAGAWA \& MOLLER (1979). Os mine rais considerados acessórios também são bastante variáveis, como caulinitas, micas, quartzo, feldspatos, montmoriloni tas, vermiculitas e aluminosas, lepidocrocitas, hematitas, gibbsitas e montmorilonitas. Esse fato deveria ser levado em consideração quando se pensa no aproveitamento das vărzeas da região.

MOLLER \& KITAGAWA (1982) e GAMA (1986) encon traram Podzólicos Vermelho-Amarelo Vérticos do Acre, apresen tando composição mineralógica bastante distinta. Estes so los, cuja gênese ainda não está bem definida, tem um conjun to de caracteristicas pouco comuns para a região, como alta capacidade de troca de cátions, teores de cálcio trocável va riando de 0,03 a $20 \mathrm{meq} / \mathrm{l} 00 \mathrm{~g}$ de solo, aluminio trocável des de 0 a 15 meq/loog de solo e relação $\mathrm{Ki}$ desde 1,54 até 3,55. Análises qualitativas e semi-qualitativas feitas nas suas frações coloidais inorgānicas mostraram que o teor de mine rais 2:1 é inversametne proporcional ao teor de "amorfos" norgānicos, posteriormente confirmados por GAMA et alii (1991) como sendo material alofānico. 


\title{
2.2. Caulinitas de solos dả Região Amazōnica
}

\begin{abstract}
Generalizaçōes têm sido feitas quanto ao com portamento das caulinitas, não tendo sido considerada como uma familia de minerais e cuja estrutura 1:1 apresenta varia ções na sobreposição das camadas, tamanho e perfeição morfo lógicas dos cristais (RANGE et alii, 1969; KITAGAWA \& MOLLER, 1980). A repetibilidade das células unitárias desses mine rais nos eixos $a$ e b, que se reflete na morfologia e no ta manho dos cristais cauliniticos, por certo influenciará no seu comportamento físico-químico, a exemplo do que observa ram MOLLER \& KLANT (1984).
\end{abstract}

Na busca dessas diferenças tem-se utilizado o indice de Hinckley (HINCKLEY, 1963) para determinar a crista Iinidade relativa dos minerais cauliniticos. Mas esse índi ce, que relaciona a intensidade das difrações (111) e (110) dos minerais cauliniticos, não é utilizado para classificar a desordem estrutural dos mesmos. Além desse indice, a pro priedade de determinados compostos orgānicos, formados por molëculas de tamanho e polaridade adequados, de reagirem em diferentes niveis com as caulinitas (JACKSON, 1962; JACKSON \& ABDEL-KADER, 1978 e HATTORI et alii, 1979) tēm sido útil para distinguir caulinitas, haloisitas e cloritas.

Um desses compostos, a hidrazina, foi utiliza do por RANGE et alii (1969), numa tentativa de classificar as caulinitas. Esses autores obvservaram tipos de reações en 
tre o composto e o mineral (tipo I, tipo II, tipo III, tipo IV), sem que houvesse havido no entanto, um limite nitido en tre eles. A haloisita, que apresenta um outro tipo de compor tamento, foi considerada por eles como um grupo à parte.

Nos solos da Região Amazōnica brasileira en contram-se desde caulinitas bem ordenadas até minerais inter mediários entre caulinitas e haloisitas (KITAGAWA \& MOLLER, 1980) e "fire clay" (MOLLER \& ARAKI, 1984). O grau de desor dem desses minerais tem sido atribuido aos teores de óxidos de ferro presentes nos solos (KITAGAWA \& MOLLER, 1980), pois tem-se encontrado alta correlação entre o conteúdo de $\mathrm{Fe}_{2} \mathrm{O}_{3}$ e a altura das difrações (001); esta se torna cada vez mais alargada como o aumento do teor de ferro (CHAUVEL et alii, 1976). O mesmo tipo de associação foi encontrado por MOLLER \& KLAMT (1984), enquanto MOLLER \& ARAKI (1984) encontraram caulinitas tipo "fire clay", a mais desordenada e reativa de las, em um latossolo amarelo com baixo teor de $\mathrm{Fe}_{2} \mathrm{O}_{3}$; portan to há que se examinar previamente o tipo de caulinita para posteriormente estudar as reatividades dos óxidos de ferro das argilas dos solos.

\subsection{Oxidos de ferro das argilas dos solos}

Hematitas e goethitas têm sido os óxidos mais frequentes nos solos da Região Amazōnica. As goethitas $(\alpha \mathrm{FeOOH})$ são relativamente abundantes nos Latossolos Amare 
los, Latossolos Vermelho-Amarelos e nos Podzólicos, enquanto as hematitas predominam nas Terras Roxas Estruturadas, Latos solos Vermelho-Escuros e Latossolos Roxos (KITAGAWA \& KIAMT, 19841.

Como caracteristica importante dos dois mine rais de ferro, hematitas e goethitas, encontrou-se nos solos da região indícios de alta substituição isomórfica do ferro por aluminio (KITAGAWA, 1983 e MOLLER \& KLAMT, 1984) que se reflete no deslocamento das difrações (111) e (110) das goe thitas e (110) das hematitas (NORRISH \& TAYLOR, 1961; JANOT et alii, 1971; KITAGAWA, 1983 e SCHWERTMANN et alii, 1979). Outras difrações também sofrerão deslocamento e podem even tualmente ser utilizadas para avaliação da substituição iso mórfica, pois o $\mathrm{Al}^{+++}$é menor que $\mathrm{Fe}^{+++} ;$os raios iōnicos desses elementos são respectivamente, $0,53 \AA$ e $0,65 \AA$.

A quantidade máxima de $\mathrm{Al}^{+++}$na estrutura das goethitas, segundo FITZPATRICK \& SCHWERTMANN (1982) baseado em sintese de laboratório, é de 33 moles de alumínio por cen to. Já para as hematitas foram encontrados valores máximos de 16 a 17 moles de alumínio por cento, pois o alumínio em maior quantidade impediria a cristalização da hematita, ha vendo formação de gibbsita e bayerita (SCHWERTMANN et alii, $1979)$.

$$
\text { Discordando um pouco desses resultados, }
$$
BRONEVOI \& FURMAKOVA (1975) sintetizaram goethitas com até 47 moles por cento de alumínio e FEY \& DIXON (1981) obtive 
ram goethitas com até 40 moles de aluminio por cento. Dados obtidos em solos mostraram goethitas com até 46 moles de alu minio por cento (FEY \& Le ROUX, 1977) e hematitas com 25 mo ies por cento de alumínio (KITAGAWA, 1983).

O efeito da substituição isomórfica de ferro por aluminio tem sido enfatizado como sendo a diminuição do tamanho das particulas (SCHWERTMANN et alii, 1979; AINSWORTH \& SUMMER, 1985) e, consequentemente, na maior reatividade dos minerais de ferro (AINSWORTH et alii, 1985).

No estudo dos óxidos de ferro, um dos proble mas que se tem notado, sobretudo na avaliação das substitui ções isomórficas de alumínio nos óxidos de ferro dos solos, é quanto à metodologia a ser utilizada. A determinação de alu minio no extrato citrato-ditionito-bicarbonato à quente (MEHRA \& JACKSON, 1959), tem o incoveniente de superestimar - valor do alumínio em solos, pela dissolução da partículas de argilominerais silicatados não bem cristalizados que por ventura estejam presentes nas amostras (SCHWERTMANN, 1985). Este incoveniente poderia, no entanto, ser anulado pelas ex trações à temperatura ambiente. Ocorre ainda a possibilidade de extrações incompletas dos óxidos, pela resitência à oxidą ção que parte deles oferece, como notaram CURI \& FRANZMEIER (1984). Por outro lado, a concentração dos óxidos de ferro pelo método de NORRISH \& TAYLOR (1961), visando facilitar o exame de difratometria de raios $x$, pode ocasionar a dissolu ção de goethitas e posterior cristalização com parte do alu 
minio da solução (KAMPF \& SCHWERTMANN, 1982). Segundo os au tores, o problema pode ser contornado pela adição de silicio antes do ataque $\mathrm{Com} \mathrm{NaOH} 5 \mathrm{~N}$.

A concentração dos óxidos de ferro permite, com $\circ$ uso de padrão interno adequado, avaliar por difratome tria de raios $x$, a substituição isomórfica do aluminio, as sim como a dimensão média dos cristais (MCD) com um erro má ximo de 2,6 moles de aluminio por cento (BRYANT et alii, 1983 e SCHULZE, 1984). Vale salientar, no entanto, que tanto os métodos químicos como as médias do deslocamento das difra ções de raios $\mathrm{X}$ fornecem a média ponderada dos valores da substituição isomórfica.

A medida da substituição isomórfica, como foi citado anteriormente, pode ser encarada como uma avaliação indireta do tamanho das particulas dos minerais de ferro (SCHWERTMANN et alii, 1977).

Nos solos da Região Amazōnica foram encontra das hematitas com substituições isomórficas bastante eleva das (24 moles de alumínio por cento) e este mineral, quando observado ao microscópio eletrōnico, apresentou característi cas de ferrihidrita, que tem grande área superficial especí fica (KITAGAWA, 1983), concordando com as associações entre o teor de aluminio estrutural e o tamanho das particulas.

Para as goethitas, altas quantidades de alumí nio estrutural (superior a 30 moles de aluminio por cento), levariam também à formação de pequenos cristais até a comple 
ta inibição da cristalização do mineral (GASTUCHE et alii, 1964 e AINSWORTH \& SUMMER, 1985). Não se conhecem trabalhos que evidenciem esta associação nos solos da Região Amazónica.

A substituição isomórfica também afeta a fací lidade de dissolução do mineral de forma indireta; diminuin do o tamanho das particulas haveria maior facilidade de dis solução (SCHWERTMANN, 1984). Assim, no que se refere às goe thitas, FITZPATRICK \& SCHWERTMANN (1982) associaram sua alta estabilidade nos solos à sua estrutura e à substituição iso mórfica devido ao fenōmeno conhecido por "releasing strutural strain".

Com a diminuição do tamanho das partículas, haveria ainda o aumento da área superficial e, conseqülente mente, um aumento das cargas superficiais dos minerais, que proporcionaria maior reatividade aos mesmos (BORGGAARD, $1983)$.

Aparentemente, no entanto, podem ocorrer duas possibilidades para a gênese das goethitas nos solos: a) no primeiro caso, os miferais de ferro apresentam a quantidade de aluminio estrutural e o tamanho dos cristais como variá veis independentes entre si, refletindo um ambiente de forma ção que propicia uma cristalização lenta em presença de gran des quantidades de alumínio, o que diferenciaria esses mine rais de ferro dos b) neoformados em ambiente onde o teor de alumínio estrutural estaria relacionado ao tamanho das partí culas devido à precipitação do ferro da solução em baixas 
condições de pressão e temperatura.

\subsection{Sorção de fósforo}

Dentre os solos anteriormente citados, os la tossolos e os podzólicos têm sido intensivamente utilizados na agricultura da Região Amazōnica. Estes solos são quimica mente pobres, com marcantes caracteristicas de sorção de fós foro aplicado, o que vem comprometendo sua produtividade.

os óxidos de ferro são, notadamente, os gran des responsáveis por esta sorção, mas um estudo detalhado das caracteristicas desses óxidos e suas reatividades requer o prévio conhecimento da fração silicatada sempre presente em grandes quantidades na fração argila dos solos, já que a fração não ferrosa muito contribui nos resultados finais da sorção (MOLLER \& KLAMT, 1984). A metodologia a ser utilizada nas observações dos óxidos de ferro depende, em grande parte dos minerais que serão dissolvidos ou concentrados.

Outra forma de estudar a reatividade dos óxi dos de ferro frente ao fósforo seria a seleção de amostras com óxidos de ferro de variadas caracteristicas mas com a fração caulinitica a mais constante possivel para evitar-se a inclusão de variáveis desnecessárias.

No que diz respeito aos óxidos de ferro, cor relações têm sido obtidas entre estes e a sorção de fósforo, mantidas constantes as demais condições. Uma dessas correla 
ções mostra que, quanto maior o teor de óxidos de ferro, maior a sorção (SING et alii, 1983); por outro lado, as pro priedađ̄es mineralógicas dos óxidos também influenciam no fe nömeno de sorção, sendo consideradas as mais importantes, os tipos dos sitios expostos, suas cargas e quantidades.

Os sítios, são basicamente função do tipo de mineral e do seu arranjo estrutural, que expõe faces, onde predominam sitios potencialmente diferentes (PARFITT, 1978) cuja carga será determinada pelo pH do ponto de carga zero do mineral, e do meio e, sua quantidade condicionada ao grau de cristalinidade do mineral (UEHARA \& GILLMAN, 1981).

As caulinitas, por possuirem nas suas superfí cies quebradas sitios dependentes do $\mathrm{pH}$, de certa forma se assemelham aos óxidos na sorção de fósforo, mas diferem quan to ao pcz e estrutura, o que, por certo, determinará cargas e tipos de sitios peculiares a cada um deles (UEHARA \& GILLMAN, 1981).

Dentre os dois minerais de ferro, hematitas e goethitas, o último tem uma estrutura mais propícia à sorção do fósforo que o primeiro. No entanto, parece que a quantida de de anion sorvida por esses minerais sofre maior influên cia das suas superficies especificas do que das diferenças de estrutura e composição (SCHWERTMANN \& TAYLOR, 1977).

BIGHAM et alii (1978), embora tenham encontra do maior sorção de fósforo em argilas amarelas, não descar tam a importāncia da área superficial, a qual, para um mesmo 
mineral, ë mais importante do que o pH (BACHE, 1964) determi nante da carga dos sitios.

No que se refere às caulinitas, testes de sor ção de fósforo têm mostrado que a caulinita padrão, bem cris talizada, é pouco efetiva na sorção (DIEz, 1980), enquanto a quelas extraidas dos solos, com menor cristalinidade, são bem mais eficientes (BAJWA, 1981). Este fato, certamente, de ve-se à peculiaridade dos sitios potenciais das caulinitas, citados anteriormente. Portanto, dentre todas as caracterís ticas mineralógicas, a quantidade dos sitios expostos nas su perficies das caulinitas e dos minerais de ferro parece ser - fator mais importante no estabelecimento da sorção máxima de fósforo.

A quantidade de sitios expostos de um mineral tem sido avaliada indiretamente pela sua superficie especifi ca. No entanto, esta medida nos óxidos de ferro no solo pode ser eventualmente, diretamente proporcional à substituição isomórfica, como foi citado anteriormente. 


\section{MATERIAL E METODOS}

Foram estudados os óxidos de ferro dos hori zontes $\mathrm{A}_{1}$ e $\mathrm{B}_{2}$ de sete Latossolos da Região Amazōnica, sendo trés Latossolos Amarelos (LA), dois Latossolos Vermelho-Ama relos (LV) e dois Latossolos Roxos (LR), cujas localizações e algumas caracteristicas físicas e químicas são mostradas nos Quadros 1 e 2. Esses latossolos foram anteriormente cą racterizados por REGO et alii, 1982 (LA 1 e 2), SANTOS et alii, 1982 (LA 3 e 4), REGO et alii, 1981 (LA 5 e 6), SANTOS et alii, 1982 ( $\operatorname{LV} 7$ e 8), GAMA et alii, 1983 ( LV 9 e 10), REGG et alii, 1984 (LR 1I) e GAMA \& MOLLER, 1982 (LR 12 e 13).

\subsection{Separação de Argila}

Após a TFSA dos solos sofrer remoção da maté ria orgānica pela $\mathrm{H}_{2} \mathrm{O}_{2}$ a $10 \%$ à temperatura ambiente e a quen te (JACKSON, 1956), a fração argila foi separada por sedimen tação natural. A suspensão em água foi obtida após a adição de $\mathrm{NaOH} 0,1 \mathrm{~N}$ até $\mathrm{pH} 8,5$ e agitação vigorosa por 3 minutos em ultra-som. As sifonações foram feitas em tempos previamen 


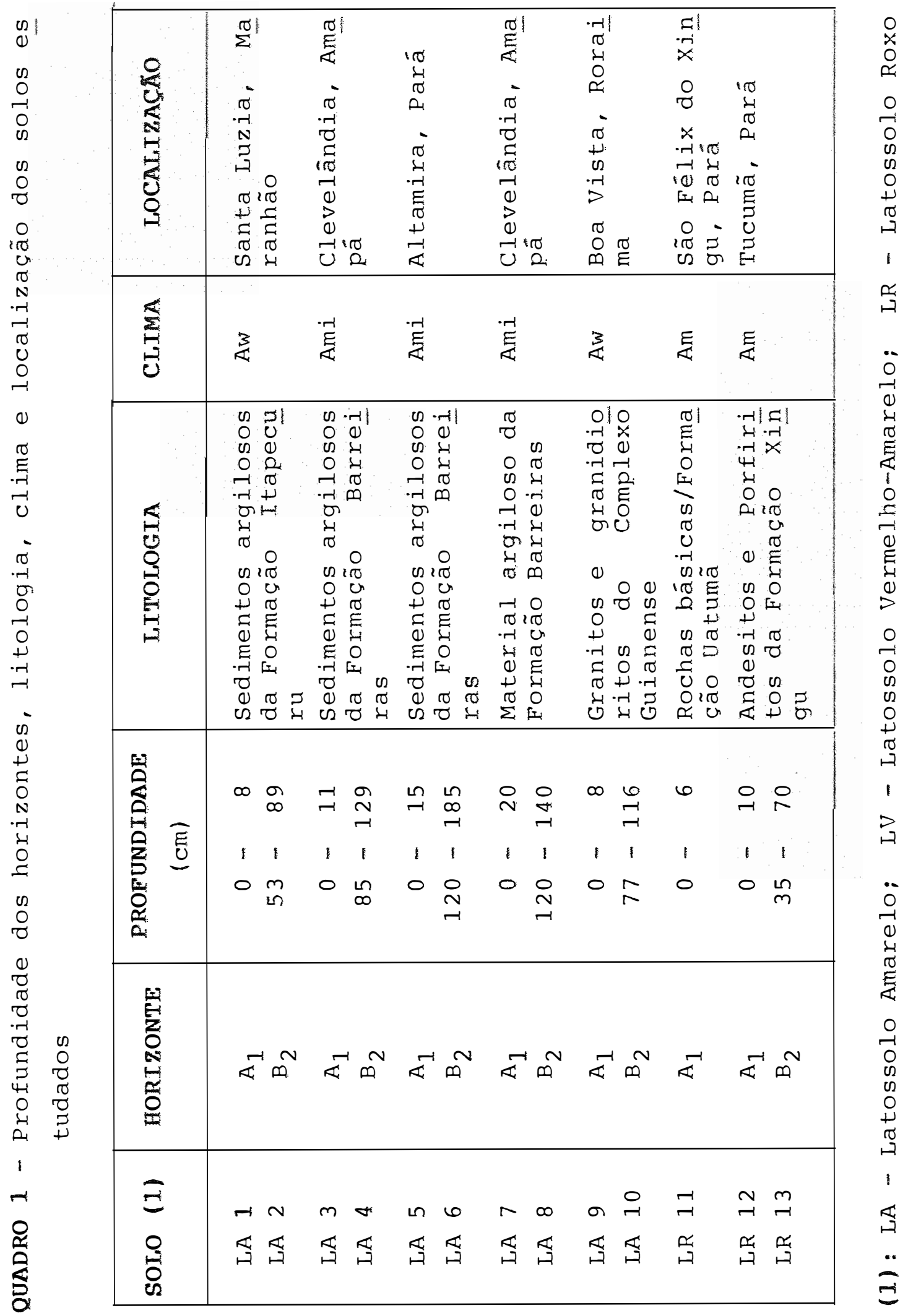




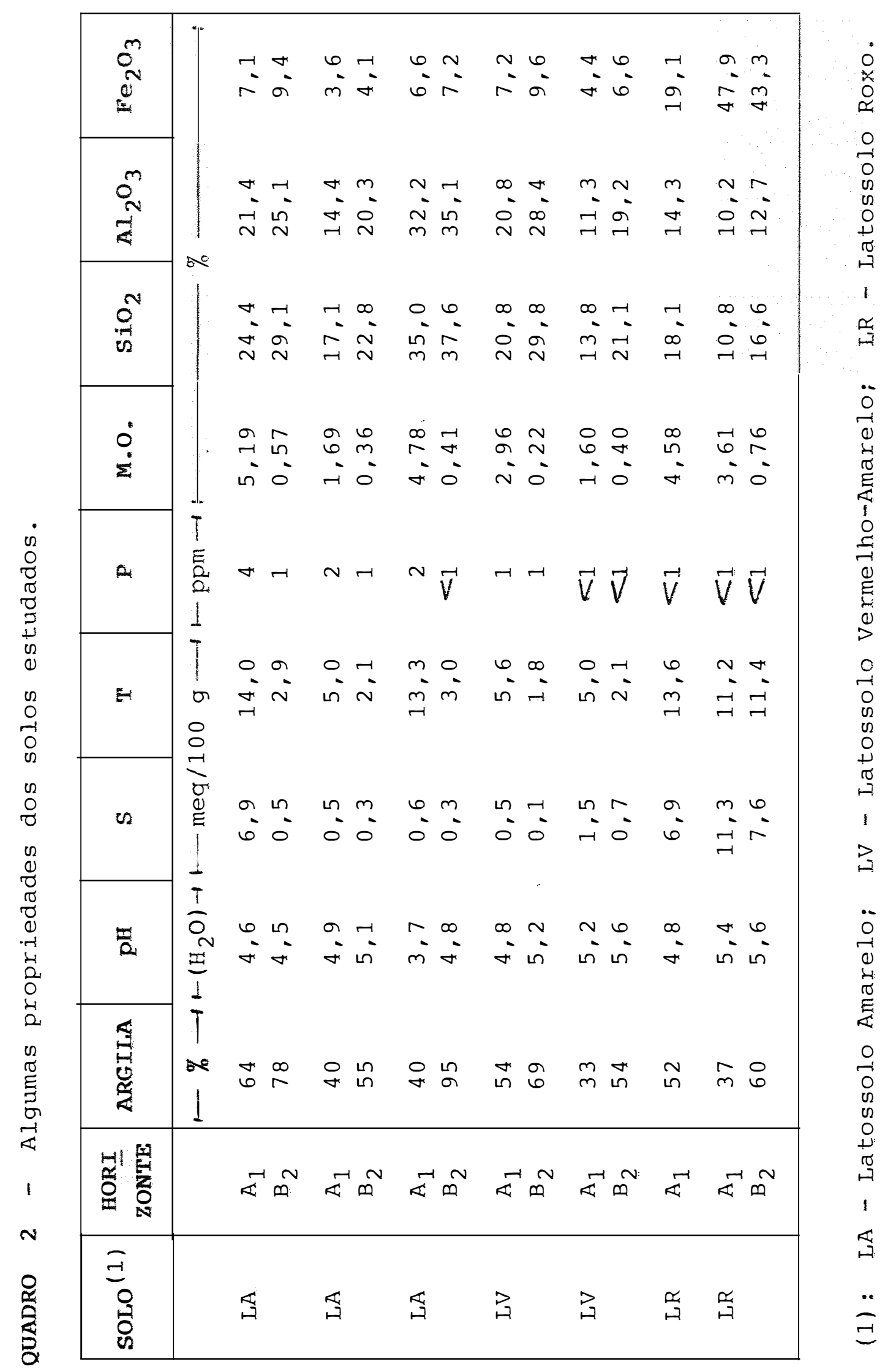


te calculados pela lei de stokes conforme o nomograma de TANNER \& JACKSON (1947), levando em consideração a temperatu彑 ra da suspensão. As amostras foram então floculadas pelo a baixamento do $\mathrm{pH}$ com $\mathrm{HCl}$, saturadas com $\mathrm{Ca}^{++}$pelo $\mathrm{CaCl}_{2}$ e la vadas em centrifugas até a ausēncia de ions cloreto. Poste riormente foram liofilizadas, moídas e peneiradas através de peneiras de 270 mesh.

\subsection{Concentração dos óxidos de ferro}

Os óxidos de ferro utilizados na difratome tria de raios $X$ foram concentrados a partir da fração argila dos solos estudados, por ataques sucessivos com $\mathrm{NaOH} \quad 5 \mathrm{~N}$ (NORISH \& TAYLOR, 1961) já que a quantidade de silício prẹ sente nas amostras era suficiente para prevenir a superesti mação do alumínio na estrutura dos minerais de ferro (KAMPF \& SCHWERTMANN; 1982). Posteriormente, as amostras foram lava das repetidas vezes com $\mathrm{HCl} 0,01 \mathrm{~N}$ e água, liofilizadas e moías ligeiramente em graal de ágata.

\subsection{Métodos químicos da avaliação da substituição isomórfica do alumínio}

A TFSA e a fração argila dos solos estudados sofreram ataques com citrato-bicarbonato-ditionito (CBD) se gundo MEHRA \& JACKSON (1959) para a solubilização dos óxidos 
de ferro e liberação do aluminio de suas estruturas. O ferro e o aluminio solubilizados foram quantificados nas soluções por absorção atõmica.

Para avaliar a eficiência do método e possi veis superestimações do alumínio isomórfico nas amostras de vido a outras fontes de alumínio (SCHWERTMANN, 1985), as fra ções $<2 \mu$ separadas dos solos foram atacadas pelos mesmos reagentes ( $C B D)$ mas em condições ligeiramente modificadas do método original de MEHRA \& JACKSON (1959) conforme mostrado a seguir.

Método CBD II - Foram utilizados 500mg de ar gila, 200ml de solução de citrato-bicarbonato e $4 \mathrm{~g}$ de ditio nito à temperatura ambiente. A agitação foi contínua por 16 horas com borbulhamento de $\mathrm{N}_{2}$ nas primeiras duas horas.

Método CBD III - Foram utilizados $100 \mathrm{mg}$ de ar gila, 20ml de solução de citrato-bicarbonato e $4 \mathrm{~g}$ de ditioni to com agitação contínua à temperatura ambiente por 24 ho ras.

Método CBD IV - Foram utilizados 30mg de argí la, 20mI de solução de citrato-bicarbonato e $1 \mathrm{~g}$ de ditionito a quente $\left(80^{\circ} \mathrm{C}\right)$ com agitação contínua por 24 horas.

Método CBD V - Foram utilizados $30 \mathrm{mg}$ de argi la, 20m de solução de citrato-bicarbonato e Ig de ditionito à temperatura ambiente, com agitação contínua por 16 horas. Avaliações do poder de complexação do citrato de sódio a quente sobre o alumínio dos filossilicatos foram 
obtidas por trēs ataques sucessivos da solução de citrato-bi carbonatos a quente. O teor de alumínio foi determinado nos extratos por absorção atômica. Os resultados foram analísa dos pelos testes de correlação simples entre os vários méto dos.

\subsection{Determinação da ārea superficial específica}

As áreas superficiais específicas dos óxiàos de ferro separados das argilas foram determinadas pelo méto do do etileno glicol monoetil éter (CARTER et alii, 1965).

\subsection{Testes de dissolução dos óxidos de ferro}

Os testes de dissolução dos óxidos de ferro foram efetuados em 100mg dos óxidos separados das argilas por ataques com NaOH 5N (NORRISH \& TAYLOR, 1961).

A proporção de óxidos, de solução de citrato-bicarbonato e, ditionito utilizada foi de $1 \mathrm{~g}: 200 \mathrm{ml}: 5 \mathrm{~g}$ com a gitação constante, a temperatura ambiente. A cada doze ho ras, as soluções foram trocadas até o desaparecimento da co loração amarela ou vermelho das amostras. O teor de ferro e de aluminio, das amostras foi medido no sobrenadante por absor ção atōmica. No decorrer do processo, algumas amostras subme tidas à difatometria de raios $\mathrm{X}$ após a adição de $10 \%$ de síli ca como padrão interno. 


\subsection{Difatometria de raios $\mathrm{X}$}

As amostras, algumas com $10 \%$ de silica agindo como padrão interno, foram montadas em suportes de aluminio com 11 x $20 \mathrm{~mm}$ de área da amostra, pressionando-se vigorosa mente o material colocado na parte posterior do suporte con tra um papel liso, para minimizar a orientação preferencial das particulas. Os dados da difratometria de raios $\mathrm{X}$ foram obtidos com radiaçōes Co - Ka (30kV e $25 \mathrm{~mA})$ em goniōmetro vertical Philips PW 1050 equipado com sistema de fendas de $1^{\circ} \mathrm{DS}, 0,2 \mathrm{~mm}$ RS e $1^{\circ} \mathrm{SS}$, monocromador de grafites e detector proporcional. Os gráficos de raios $x$ foram obtidos por "step scanning" de $23,5^{\circ}$ a $26,5^{\circ}$ àngulo $2 \theta, 36^{\circ}$ a $46^{\circ}$ e $35^{\circ}$ a $60^{\circ}$ ângulo $2 \theta \operatorname{com} 0,050$ e $0,020^{\circ}$ de incremento $2 \theta$ por 20 segun dos.

3.7. Medida da posição das linhas de difração đe raios $\mathrm{X}$ e cálculo da substituição isomórfica

Cuidados especiais foram tomados na medida da posição das linhas de difração, já que estas refletem a subs tituição do ferro pelo aluminio nos óxidos. Os dados obti dos, juntamente com o padrão interno, foram corrigidos por computador pelas difrações da silica cujos ângulos $2 \theta$ não são coincidentes com os óxidos, mas já haviam sido examina dos exaustivamente anteriormente. A calibração do ganiōmetro 
foi feita conforme descrito por SCHULZE (1984).

O cálculo da percentagem da alumínio na estru tura dos óxidos foi feito para a goethita segundo schULzE (1984) conforme a equação:

$$
\text { mol }: \text { de } A l=1730-572 \mathrm{C}
$$

onde,

$$
c=\left[\frac{1}{d^{2}(111)}-d^{2}(110)\right]^{-\frac{1}{2}}
$$

para as hematitas foi utilizada a equação:

$$
\operatorname{mol} \therefore \mathrm{Al}=3109-617,1 \mathrm{a}
$$

onde,

$$
a=d(110) \times 2
$$

3.8. Cálculo da đimensão méđia dos cristais (MCD)

$$
\text { o cálculo da MCD foi feito pela equação de }
$$

Scherer:

$$
M C D=\frac{k x \lambda}{(B-b) \cos \theta}
$$

sendo $\mathrm{k}$ a constante 0,9 ; segundo KLUG \& ALEXANDER (1974);

$\lambda$ o comprimento de onda utilizado nas radiações de raios $\mathrm{X}, \mathrm{em} \AA$;

$\theta$ o àngulo de Bragg expresso em radianos;

B largura do pico à meia altura (wHH) em graus $2 \theta$

b foi calculado a partir da equação

$$
\text { wHHi }=0,0871+0,00144 \mathrm{X}+1,51 \times 10^{-5} \mathrm{X}^{2}
$$


onde, $\mathrm{x}$ é o grau do àngulo $2 \theta$.

Exemplos do cálculo da MCD e da substituição isomórfica de alumínio são mostrados nos anexos de 1 a 5 .

\subsection{Sorção de fósforo}

A seleção das amostras de argila para o estụ do da sorção de fósforo foi feita a partir dos dados minera lógicos das caulinitas dos solos com base no indice de Hinckley (HINCKLEY, 1963) e na classificação de RANGE et alii (1969).

As curvas de sorção de fósforo foram feitas u tilizando-se $1 \mathrm{~g}$ das amostras de argila e $50 \mathrm{ml}$ de solução de $\mathrm{CaCl}_{2} 0,01 \mathrm{~N} \mathrm{pH} 6,0$ com quantidades variáveis de $\mathrm{P}(5,10$, $15,20,30,40$ e $60 \mathrm{ppm})$ adicionado como $\mathrm{KH}_{2} \mathrm{PO}_{4}$. As amostras foram agitadas por 48 horas para acelerar o equilibrio e o $P$ remanescente foi medido no extrato por colorimetria através da formação do amarelo de vanadato. O P absorvido foi consi derado como sendo a diferença entre o adicionado e o remanes cente na solução após 48 horas. 


\section{RESULTADOS E DISCUSSÃO}

\subsection{Identificação dos minerais de ferro na fração argila}

Os difratogramas dos óxidos concentrados a partir da fração argila dos solos estudados, (Figura 1) mos tram uma difração na região de 2,69 § relativa às difrações da goethita (130) e da hematita (104). Em seguida, constata-se uma difração de aproximadamente $2,58 \AA$ correspondente à goethita (021), uma de 2,51 đa hametita (110) e uma de 2,45 relativa à goethita (111), evidenciando nestes solos, uma mistura de óxidos de ferro formada por goethita e hemati ta.

Em difratogramas dos óxidos obtidos com maior amplitude, de $18^{\circ}$ a $60^{\circ}$ àngulo $2 \theta$ (Figura 2), além dos mine rais acima citados, observa-se também traços de rutilo 13,25 $\AA)$, anatásio $(3,51 \AA, 2,38 \AA$ e $1,89 \AA)$ e quartzo $(3,35 \AA)$.

As intensidades relativas de goethitas e hema titas em cada difratograma da Figura 1 sugerem a proporção crescente de hematita do LA para LR. Já os desvios do espaça mento d para àngulos menores, deve-se por certo à substitui ção isomórfica do ferro na estrutura dos minerais, por ele 


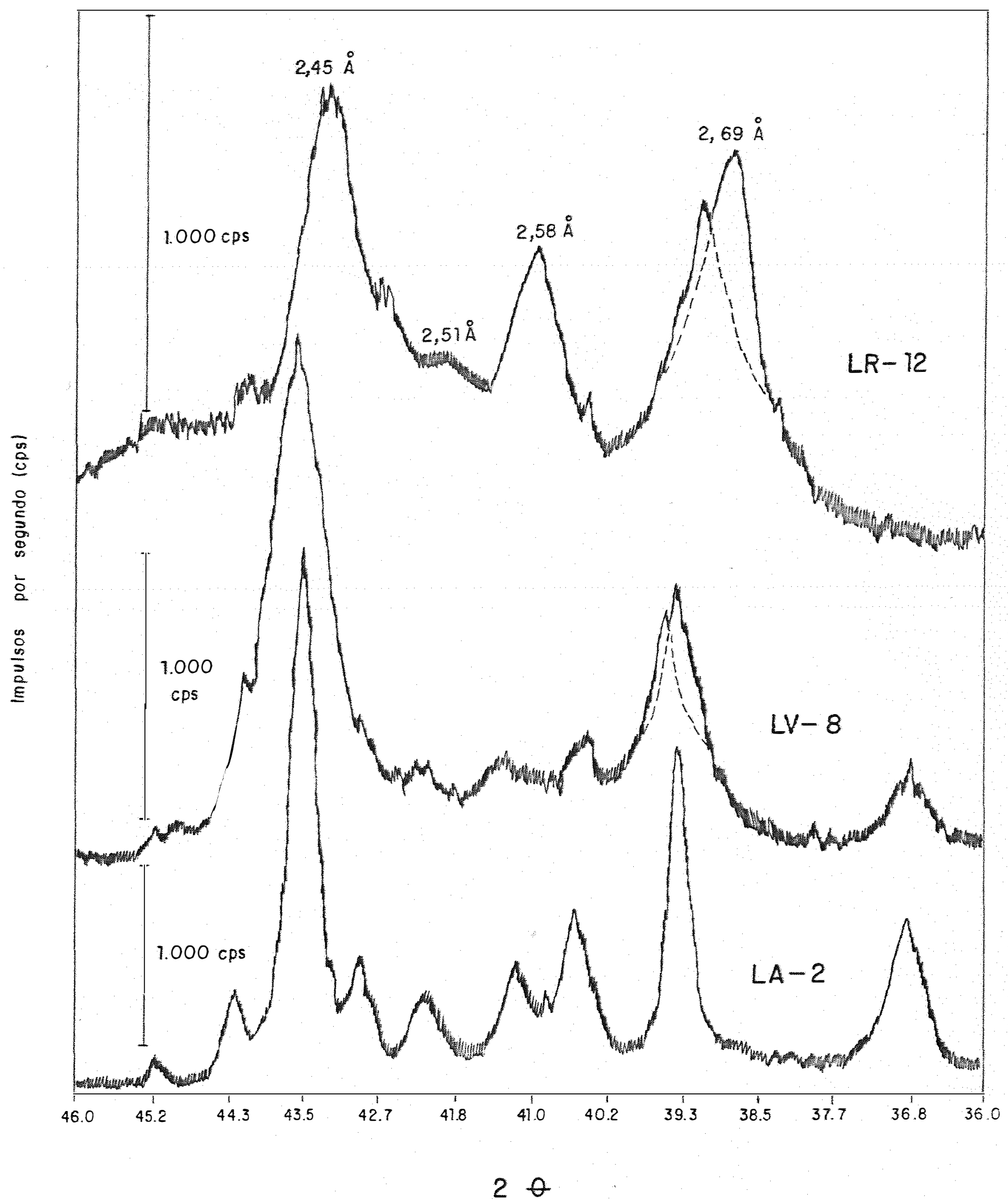

Figura 1 - Difratogramas de óxidos de ferro separados das argi las das amostras $L R_{12}, L V_{8}$ e $L A_{2}$. 


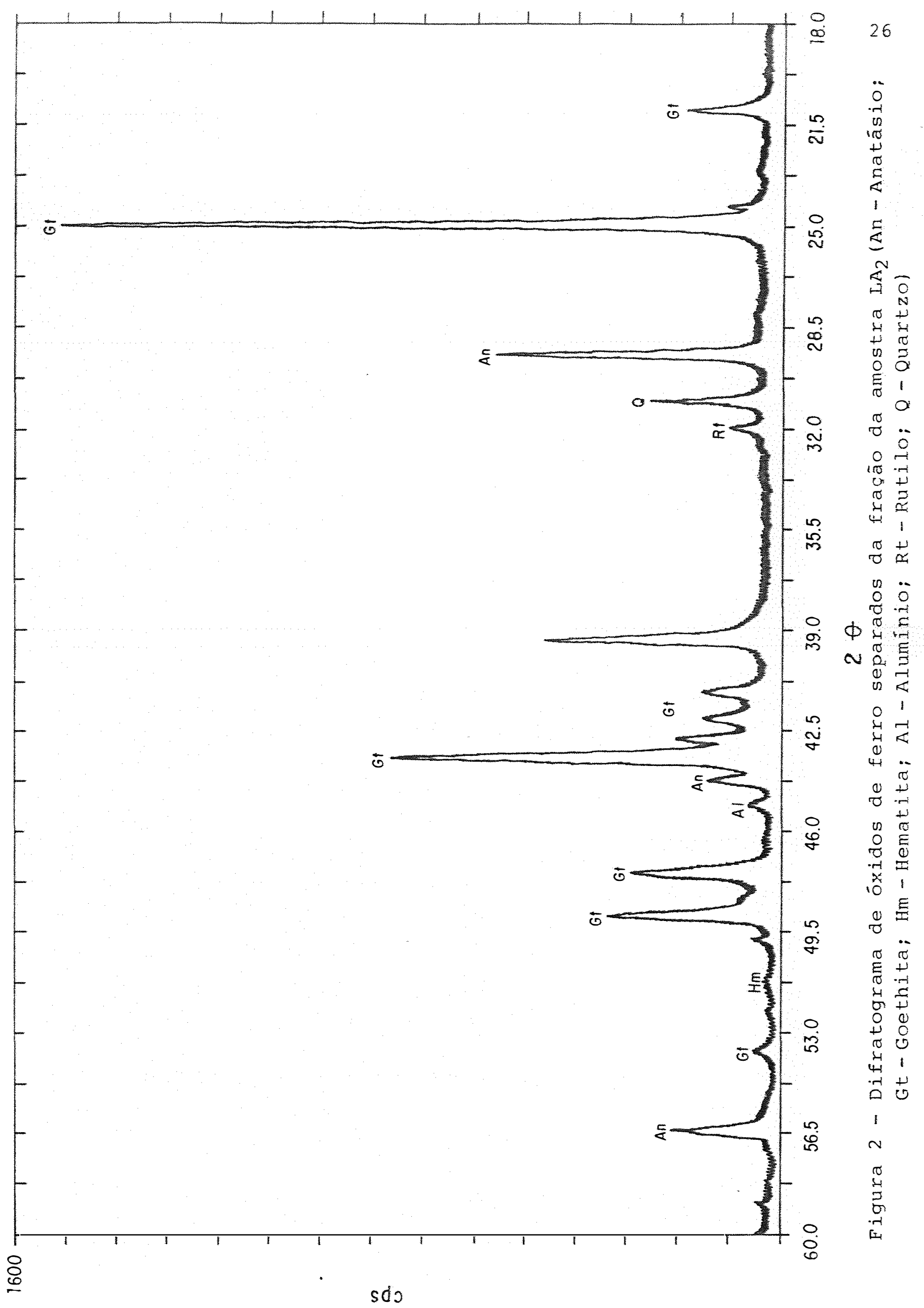


mento de raio iōnico menor. Dentre os elementos que podem e ventualmente substituir o ferro estrutural de goethitas e he matitas, o mais comum é o alumínio, tanto pela sua abundān cia nos solos pelo fato de possuirem a mesma valência $(+3)$ e um raio iónico $(0,53 \AA)$ muito próximo ao do ferro $(0,65 \AA)$. Estas substituições têm sido mostradas frequentemente na li teratura (JANOT et alii; 1971; SCHWERTMANN et alii, 1977; MENDELOVICI et alii, 1979 e KITAGAWA, 1983). Além dos des vios para àngulos menores, outra evidēncia da substituição i somórfica nos óxidos de ferro é a individualização de dois picos a aproximadamente 2,69 ; correspondente a goethita (130) e hematita (104) nos solos LV 8 e LR 12 (Figura I), pois dificilmente se esperaria quantidades iguais de AI nas estruturas destes dois minerais.

Experimentos de laboratório mostraram que ni veis altos de alumínio na solução induzem a formação prefe rencial de goethita (SCHWERTMANN et alii, 1977), e que este mineral é capaz de conter em sua estrutura, o dobro do alumí nio permitido para as hematitas, o que, eventualmente, pode estar ocorrendo nas amostras analisadas. Esta individualiza ção de picos pode ser também conseqüencia dos diferentes e feitos do alumínio nos espaçamentos planares de goethitas e hematitas.

$\mathrm{Na}$ Figura 1, as intensidades dos picos lava liados pelos cps) das hematitas e goethitas sugere que a quantidade de goethita nos solos estudados obedecem a ordem 
$L A>L V>L R$, enquanto o alargamento dos mesmos sugere uma seqüēncia inversa, $L A<L V<L R$, provavelmente devido ao tạ manho dos cristais formados, menores no LR e maiores no LA (JACKSON, 1962 e SCHWERTMANN, 1985).

4.2. Quantificação đos óxidos de ferro na TFSA e na fração argila, substituição isomórfica avaliada por métodos químicos

A quantificação dos óxidos de ferro na TESA e na fração argila dos solos estudados, obtida pelo método MEHRA \& JACKSON (1959), aqui denominado de CBD I, mostrou baixos teores de ferro nos Latossolos Amarelos e nos Latosso los Vermelho-Amarelos, em torno de 5\% de ferro enquanto nos Latossolos Roxos esses teores foram bastante significativos (Quadro 3). Há evidèncias, portanto, de que nos Latossolos estudados, quando predomina a goethita na mistura de óxidos ocorre baixa concentração de ferroe, quando predomina a he matita, alta concentração, provavelmente devido ao material de origem (Quadro 1). O alumínio solubilizado em proporção ao ferro (Al/AI + Fe) teve comportamento inverso, indicando alta substituição isomórfica deste elemento nos óxidos de ferro dos Latossolos Vermelho-Amarelos e baixa nos Latosso los Roxos (Quadro 3), dando indicação de que nos solos estu dados, as goethitas são mais aluminiosas que as hematitas. Provavelmente, então a individualização de dois picos a 


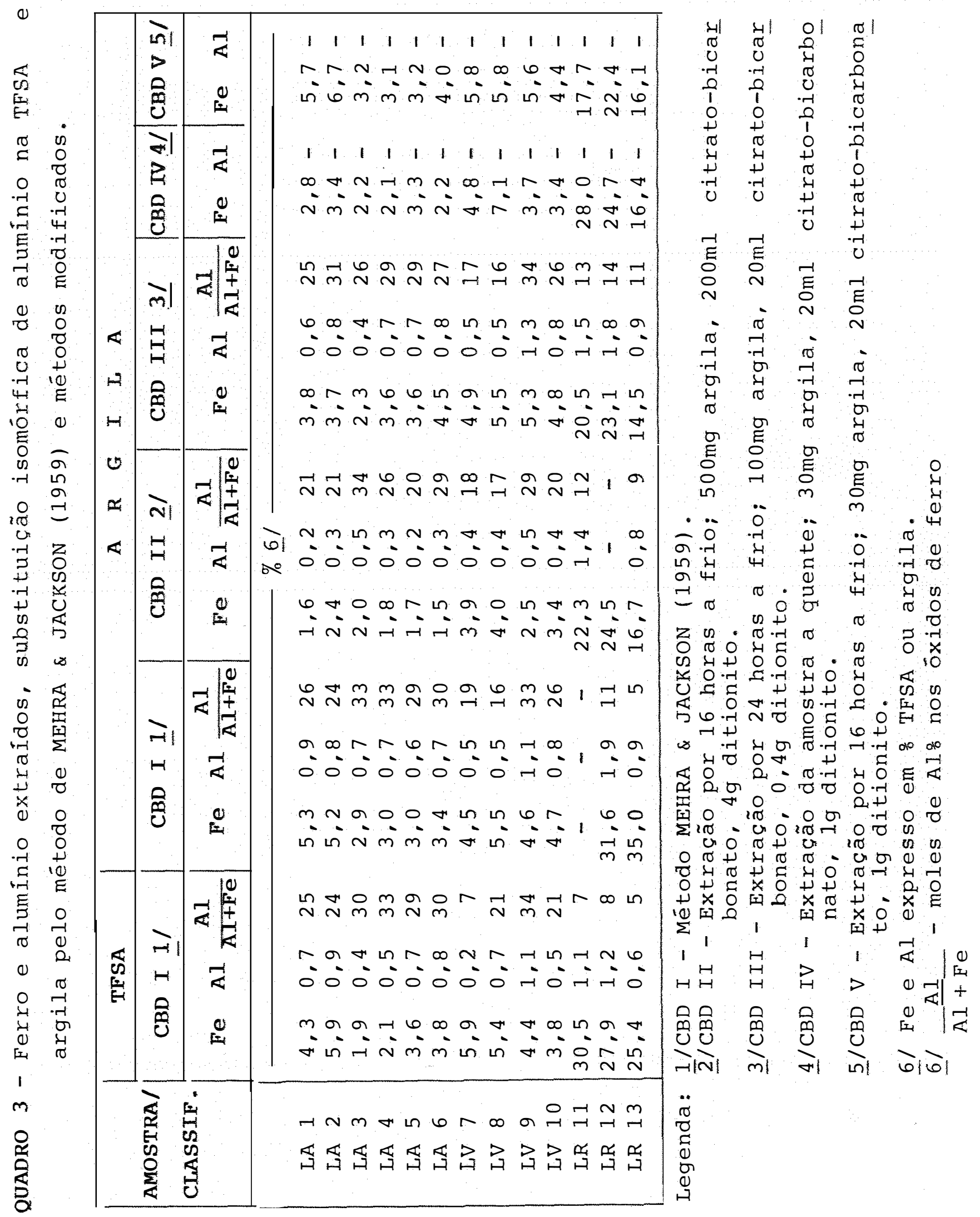


2,69 $\AA$, observada na Figura 1, seja devida ao maior grau de substituição do ferro pelo alumínio o que estaria de acordo com as observações de SCHWERTMANN (1985).

Parte da goethita dos Latossolos Amarelos e Latossolos Vermelho-Amarelos também se mostrou muito resis tente à redução pelo ditionito, método de MEHRA \& JACKSON (1959), conforme os resultados dos difratogramas da Figura 3 , onde os picos de $2,69 \AA$ e de $2,45 \AA$ das goethitas não de sapareceram completamente após o referido tratamento.

Uma das possiveis causas da ineficiēncia do CBD é o alto teor de aluminio estrutural das goethitas (CURI \& FRANZMEIER; 1984). Pode-se também inferir que o tamanho dos cristais desfavorece a rápida dissolução dos minerais (SCHWERTMANN, 1984), uma vez que a dissolução é um fenōmeno de superficie. Esta evidēncia pode ser obseryada pelas suas medidas obtidas antes e após 24 e 48 horas de extração a frio (Quadro 4). Nelas, observou-se uma ligeira diminuição da MCD com o tempo de dissolução.

Modificações foram então introduzidas no méto do original (CBD I), algumas visando diminuir a taxa de redu ção dos óxidos (modificações CBD II e III), outras com a nalidade de aumentar a ação do agente redutor (CBD V) ou am bas (CBD IV). Nota-se, de maneira geral, que para os solos estudados, os métodos que são levados a cabo à temperatura ambiente foram os menos eficientes na solubilização dos óxi dos (Quadro 3), eficiência esta aumentada com o tempo de rea 


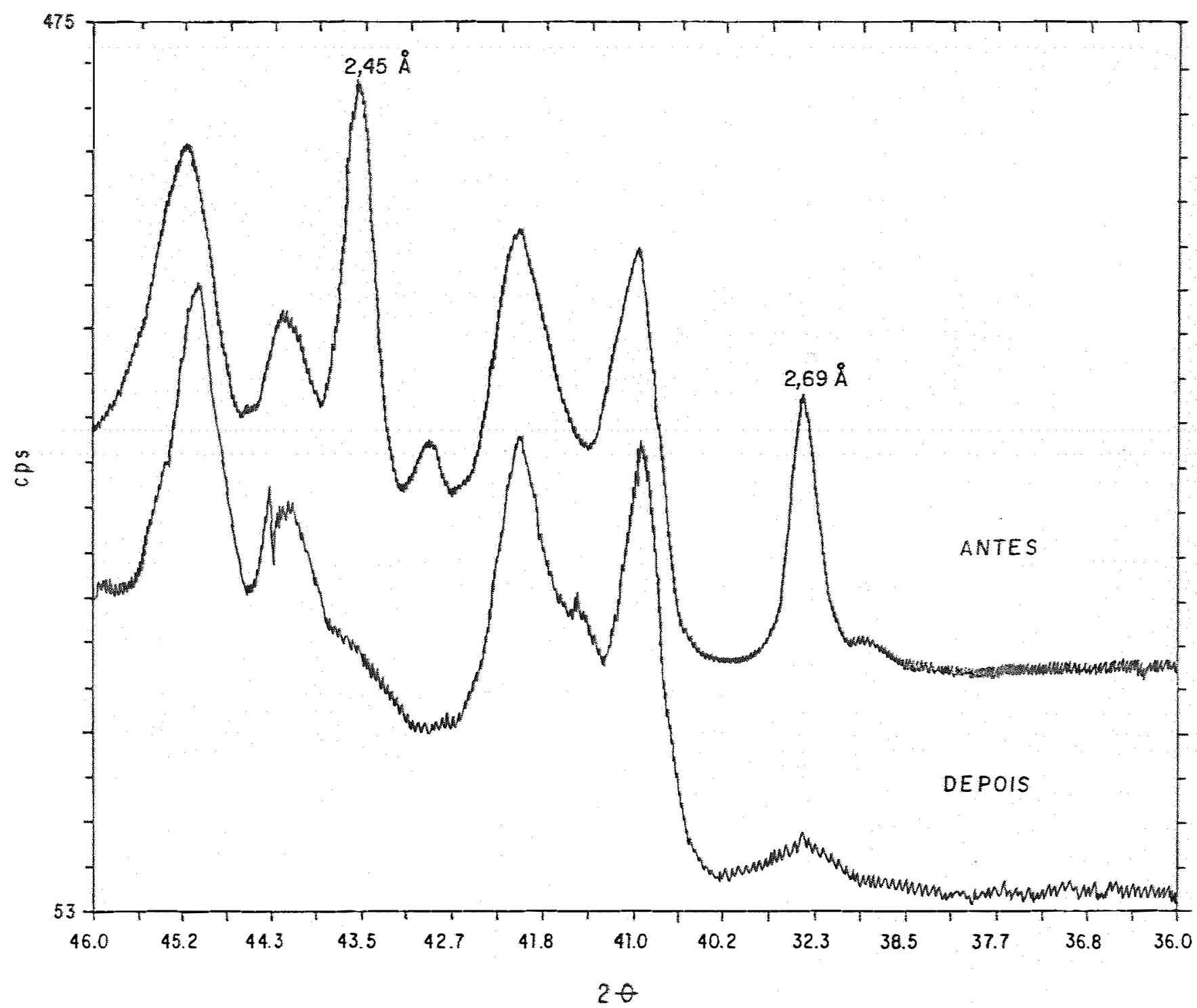

Figura 3 - Difratograma das argilas do solo $\mathrm{LA}_{2}$ antes e após o tratamento $C B D$ a quente. 
QUADRO 4 - Medidas da MCD da goethita (110) na amostra IA 2 antes e após 24 e 48 horas de extração com CBD a frio.

\begin{tabular}{|c|c|c|c|c|}
\hline & \multirow{2}{*}{$\operatorname{Kn} 1$} & \multicolumn{3}{|c|}{$\begin{aligned} \text { MODIFICAÇŌES DE ESPAÇAMENTO d COM } \\
\text { O TEMPO DE EXTRAÇÃO }\end{aligned}$} \\
\hline & & $0 \mathrm{~h}$ & $24 \mathrm{~h}$ & $48 \mathrm{~h}$ \\
\hline & 020 & 4,90812 & 4,90686 & 4,90248 \\
\hline & 110 & 4,13754 & 4,13738 & 4,13669 \\
\hline & 120 & 3,34175 & 3,34136 & 3,34010 \\
\hline & 130 & 2,65900 & 2,65856 & 2,65743 \\
\hline & 021 & 2,54773 & 2,54645 & - \\
\hline & 040 & 2,45406 & 2,45343 & 2,45357 \\
\hline & 111 & 2,41851 & 2,41754 & 2,41749 \\
\hline & 121 & 2,22444 & 2,22359 & 2,22353 \\
\hline & 140 & 2,16127 & 2,16085 & 2,16006 \\
\hline & 131 & 1,98424 & 1,98354 & - \\
\hline $\mathrm{MCD}$ & $(\mathrm{nm})$ & 102 & 96 & 85 \\
\hline Al & (mol 앙) & 25,0 & 26,0 & 25,9 \\
\hline
\end{tabular}


ção e que, a adição de grandes quantidades de ditionito, im pedem a determinação do alumínio da solução devido a alta temperatura da chama do absorção atômica. Entretanto, análi ses de correlação feitas entre os resultados obtidos pelos diferentes métodos mostraram alta correlação entre os teores de ferro solubilizados em todos eles (Quadro 5), provavelmen te devido ao pequeno percentual representado pelo mineral não dissolvido no processo.

QUADRO 5 - Correlação simples entre a porcentagem de Fe ex traido das argilas dos solos pelo método MEHRA \& JACKSON (I) e pelos métodos modificados (II, III, IV e V).

\begin{tabular}{|l|llll|}
\hline & Fe I $\underline{1} /$ & $F e I I \underline{2} /$ & $F e I I I \underline{3}$ Fe IV 4 / \\
\hline Fe I & 1 & & & \\
Fe II & $0,9522 * *$ & 1 & & \\
Fe III & $0,9233 * *$ & $0,9913 * *$ & 1 & \\
Fe IV & $0,9365 * *$ & $0,9949 * *$ & $0,9901 * *$ & 1 \\
Fe V & $0,9580 * *$ & $0,9807 * *$ & $0,9822 * *$ & $0,9766 * *$ \\
\hline
\end{tabular}

** Significatifo ao nivel de 0,01

I/ Ferro extraído pelo método de MEHRA \& JACKSON

2/ Ferro extraído pelo método CBD II

3/ Ferro extraído pelo método CBD III

4/ Ferro extraido pelo método CBD IV

De maneira semelhante, o método original de MEHRA \& JACKSON (1959) e as modificações CBD II e III tive 
ram alta correlação entre si no que diz respeito aos teores de aluminio extraído (Quadro 6) e os valores da substituição isomórfica (Quadro 7). Dada à maior operacionalidade dos mé todos levados a cabo à temperatura ambiente, sobretudo no ma nuseio de grandes quantidades de amostras além da possibili dade de interrupção da reação a qualquer momento para avalia ção tanto dos minerais não solubilizados como dos íons em so lução, acredita-se que as extrações à temperatura ambiente podem ser utilizadas com vantagem no estudo de dissoluções e estabilidade dos minerais de ferro nas argilas.

Quadro 6 - Correlação simples entre a de Al extraído dos óxidos das frações argilas dos solos pelo método MEHRA \& JACKSON (I) e peIos métodos modificados (II e III).

\begin{tabular}{|l|lll|}
\hline & AI I I/ & AI II 2/ & AI III $\underline{3}$ I \\
\hline AI I & 1 & & \\
AI II & $0,8650 * *$ & 1 & \\
AI III & $0,9249 * *$ & $0,8391 * *$ & 1 \\
\hline
\end{tabular}

** Significativo ao nível de 0,01\%

1/ Aluminio extraído pelo método MEHRA \& JACKSON

2) Aluminio extraído pelo método CBD II

3/ Alumínio extraído pelo método CBD III 
Quadro 7 - Correlação simples entre as substituições isomór ficas de ferro por alumínio, expressas em moles \%, obtidas pelo método de MEHRA \& JACKSON (I) e pelos métodos modificados.

\begin{tabular}{|l|lll|}
\hline & AI I I/ & AI II $2 /$ & AI III $3 /$ \\
\hline AI I & 1 & & \\
AI II & $0,8644^{*}$ & 1 & 1 \\
AI III & $0,9074 *$ & $0,8039 *$ & \\
\hline
\end{tabular}

** Significativo ao nivel de 0,05

I/ Substituição isomórfica do alumínio pelo método MEHRA \& JACKSON

2f Substituição isomórfica do aluminio pelo método CBD II

3/ Substituição isomórfica do alumínio pelo método CBD III

As extrações à temperatura ambiente CBD II e III) trazem como vantagem adicional a não complexação do alu minio de outras fontes que não os óxidos de ferro, o que 으 corre pela ação do citrato-bicarbonato a quente (SCHWERTMANN, $1985)$.

Nos solos estudados, os testes efetuados para avaliar o efeito da complexação do alumínio pelo citrato-bi carbonato de outras fontes que não os óxidos de ferro eviden ciam algumas influências da complexação no resultado final 
da substituição isomórfica do aluminio (quadro 8). Neste tra balho, estes valores não foram subtraidos nos resultados fi nais de teores de alumínio uma vez que as avaliações mais precisas das substituições isomórficas foram obtidas nos óxi dos de ferro previamente separados das argilas.

Dentre as caracteristicas dos óxidos de ferro avaliadas por análises rotineiras de raios $x$ e pelas análi ses quimicas efetuadas até aqui, trēs particularmente chamam atenção; a) a alta substituição isomórfica de ferro por alu minio em solos onde a goethita predomina, refletida nas aná Iises quimicas; b) a grande dimensão dos cristais das goe thitas, refletidas nas suas difrações finais e intensas em comparação às largas e difusas das hematitas; e c) a resis tência de parte dos óxidos, notadamente as goethitas, à redu ção pelo ditionito de sódio. Estas trēs características não estão de acordo com as observações de SCHWERTMANN (1979) se gundo o qual, quanto maior o grau de substituição isomórfi ca, menor o tamanho dos cristais e maior a facilidade de dis Solução (SCHWERTMANN, 1984).

As trēs caracteristicas puderam ser melhor a valiadas nas dissoluções parciais dos óxidos, onde foram ob servadas periodicamente as relações Al/AI + Fe (moles de alu minio por cento nas estruturas de óxidos de ferrol juntamen mente com medidas dos picos das difrações de raios X. As dis soluções parciais foram efetuadas unicamente nas amostras de Latossolo Amarelo e Latossolo Vermelho-Amarelo, onde a goe 


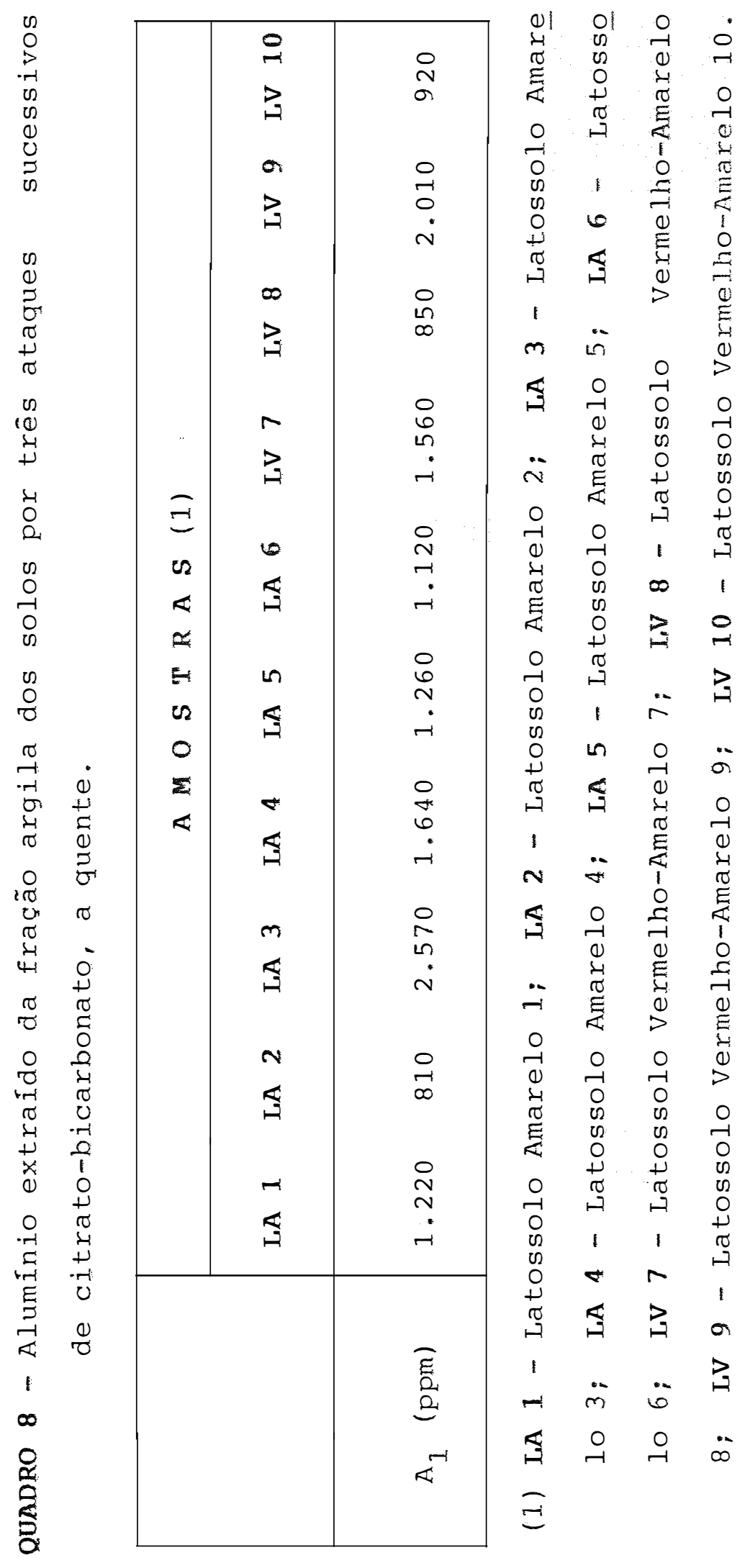


thita é o óxido predominante, uma vez que somente nelas fo ram observadas dificuldades de dissolução.

4.3. Dissoluções de óxidos de ferro: frações de óxidos de ferro com diferentes substituições isomórficas

Dissoluções de óxidos à temperatura ambiente, interrompidas a cada 12 horas para avaliação periódica da substituição isomórfica do ferro por aluminio, mostraram que nas primeiras 48 horas já haviam sido dissolvidos mais de 95\% do total dos óxidos de ferro das amostras LA 4, LV 8 e LV 10 (Quadro 9). Nas amostras LA 2 e LA 6, no mesmo perio do, foram dissolvidos algo em torno de $80 \%$ do ferro, eviden ciando, nesta última, a presença de maior quantiajade de ma terial resistente à redução pelo ditionito.

os valores de AI/AI + Fe (moles de aluminio por cento na estrutura das goethitas) nas primeiras 48 horas de dissolução variaram de 5 a 31 para todas as amostras ana lisadas, portanto, dentro dos limites máximos estabelecidos para a goethita de 33 moles de aluminio por cento (SCHWERTMANN \& TAYLOR, 1977 e SCHWERTMANN, 1985). As hemati tas, cujo valor máximo de substituição isomórfica é de 16 mo les de alumínio por cento, estariam dentro do intervalo de 33 moles por cento das goethitas; portanto, foi aqui conside rado o valor máximo permitiao para as misturas de goethitas + hematitas, de 33 moles por cento. 


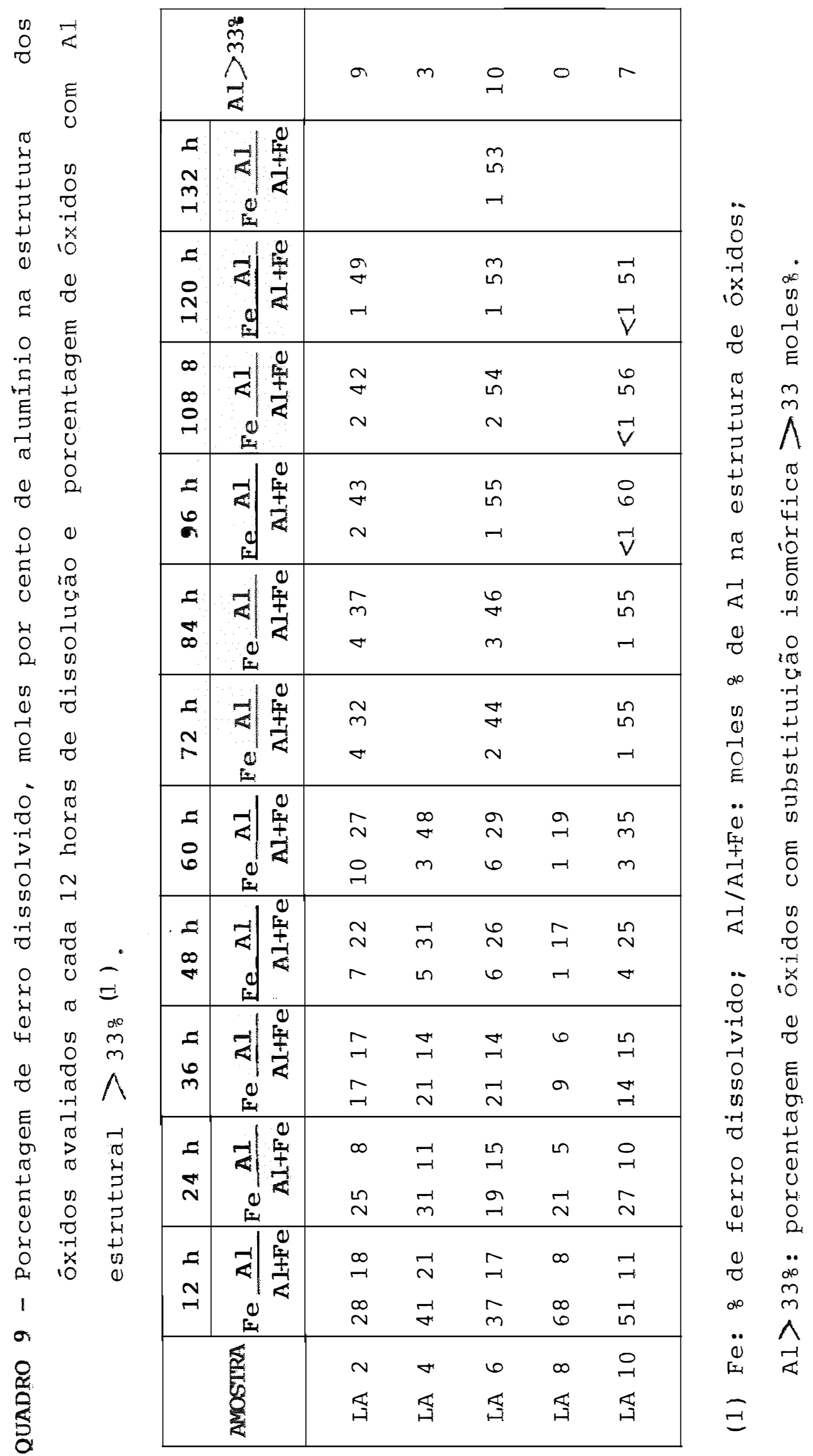


A partir de 60 horas de dissolução, começam a ser observadas elevaçōes importantes na intensidade de subs tituição isomórfica, as quais ultrapassam os 33 moles por cento de aluminio maior que os comumente observados, muito embora a quantidade destes minerais altamente aluminiosos em relação ao total de óxidos seja muito pequena, de 3 a $10 \%$ nas amostras LA 2, LA 4, LA 6 e LV 10; e zero no LV 8 (Qua dro 9).

A possibilidade do limite de 33 moles por cen to de alumínio para as goethitas, e de 16 moles por cento de alumínio para as hematitas serem ultrapassados, embora não seja comum, tem sido evidenciada tanto em sinteses de labora tório como em amostras de solos, como demostraram FEY \& DIXON (1981), BRONEVOI \& FURMAKOVA (1975) FEY \& Le ROUX, (1977) e KITAGAWA (1983). No entanto, provavelmente devido à peque na percentagem deste material nas amostras, as dissoluçōes preconizadas por MEHRA \& JACKSON (1959), que refletem a mé dia ponderada ảas substituições isomórficas, não evidenciam estas pequenas porçōes de óxidos com altos teores de alumí nio (Quadro 3). O mesmo ocorre com as medidas de substitui ções isomórficas de hematitas e goethitas tomadas separada mente por difratometria de raios $\mathrm{X}$ [difraçōes (111) e (110) para as goethitas e (110) para as hematitas] conforme se ob serva no Quadro 10. Em algumas amostras não foram considera dos os picos da hematita devido à sua pequena intensidade e grande dispersão que acarretaria num grande erro na medida 


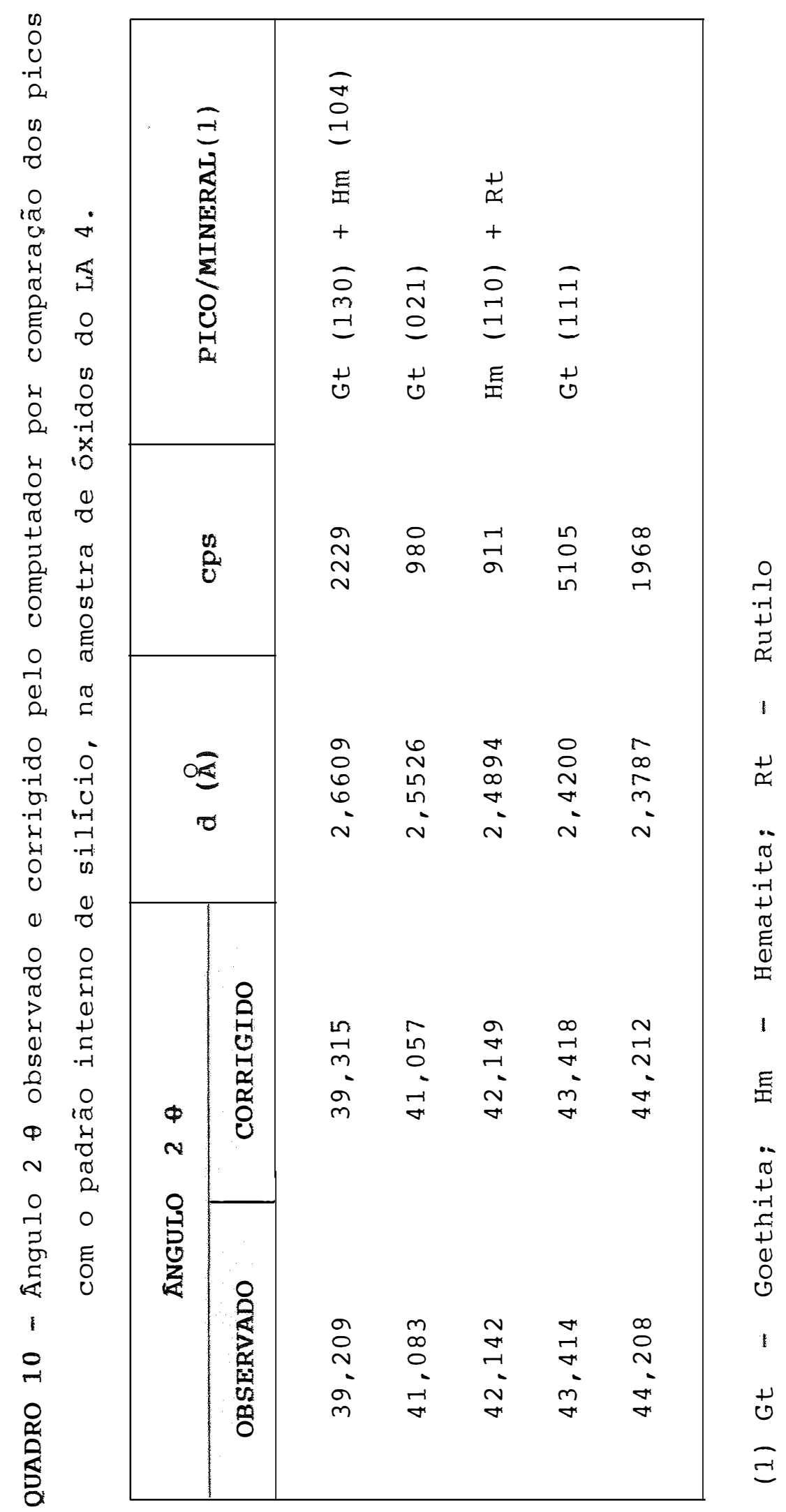


do ângulo $2 \theta$, além da presença da difração do rutilo cujo pico de 2,49 A interfere na difração da hematita (110) deslo cado pelo alumínio estrutural (Figura 4 e Quadro 10).

A dificuldade de dissolução das amostras ana lisadas certamente se deve à substituição isomórfica do fer ro por alumínio, conforme já havia sido notado por CURI \& FRANZMEIER (1984), e que também foi observado neste traba 1ho. Na Figura 5, a amostra LV 8, onde a intesidade de subs tituição isomórfica foi a menor de todas e o valor de 33 mo les de alumínio por cento não foi ultrapassado em nenhuma e tapa da reação (Quadro 9), os minerais dissolveram-se facil mente, conforme mostra sua curva de dissolução. Na amostra LA 4, cuja dissolução final dos óxidos de ferro ocorreu no mesmo intervalo de tempo que a anterior; 60 horas, a curva mais inclinada evidencia já, a presença de material resisten te à dissolução, embora em pequena quantidade, o que concor da com os dados mostrados no Quadro 9 e representados no his tograma da Figura 5.

Nas amostras IV 10, LA 2 e LA 6, o tempo to tal para a dissolução dos óxidos de ferro à temperatura am biente foi aproximadamente o dobro das primeiras, respectiva mente 120 horas, 120 horas e 132 horas, indicando haver nes tas um teor bem mais elevado de mineral resistente à oxida ção; esse fato concorda com as : de mineral com substituição isomórfica superior a 33\%, representado no histograma da Fi gura 5. No que se refere às inclinações das curvas dessas a 


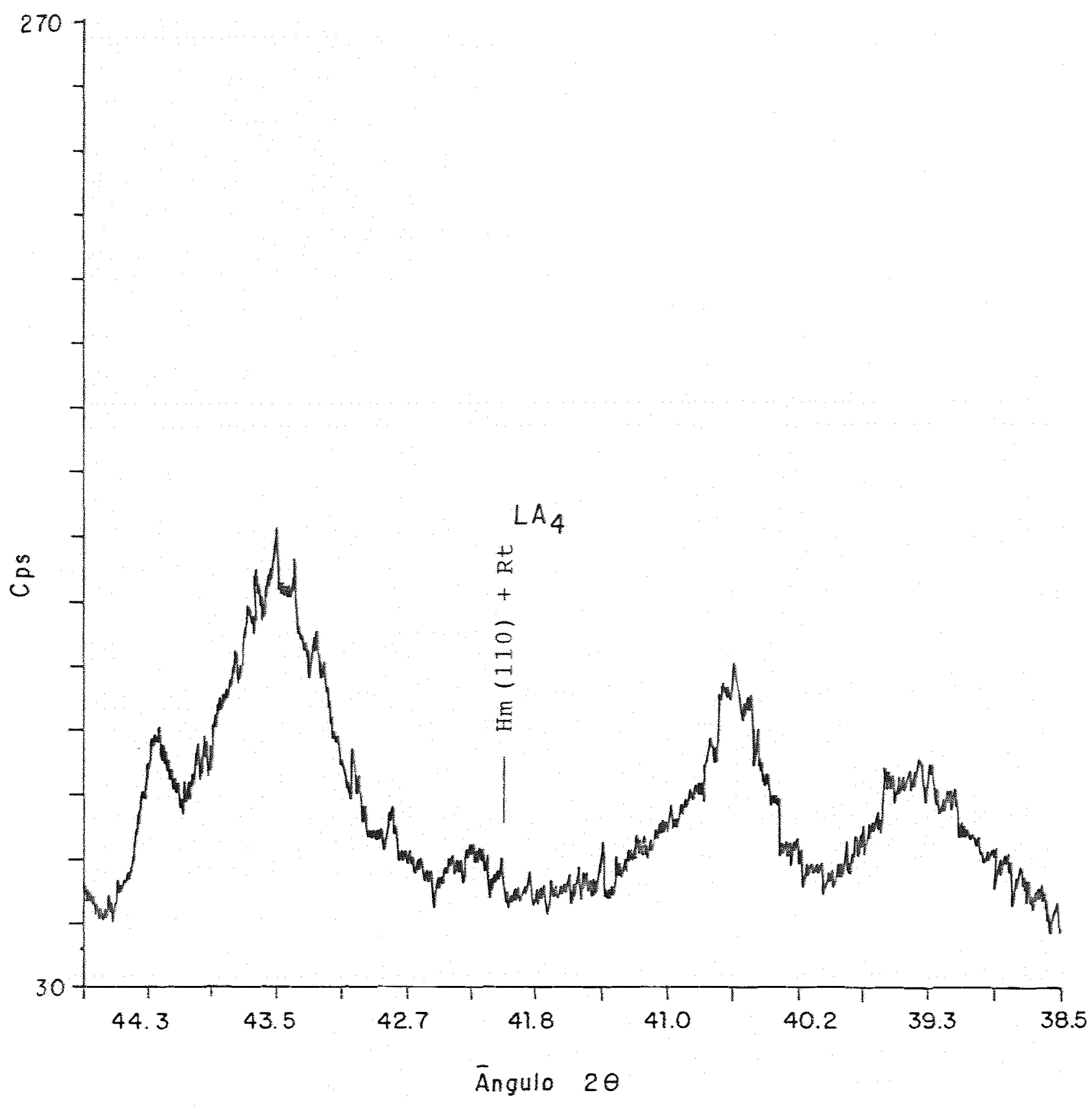

Figura 4 - Difratograma da argila do solo LA 4 (Hm - Hematita; Rt - Rutilol. 


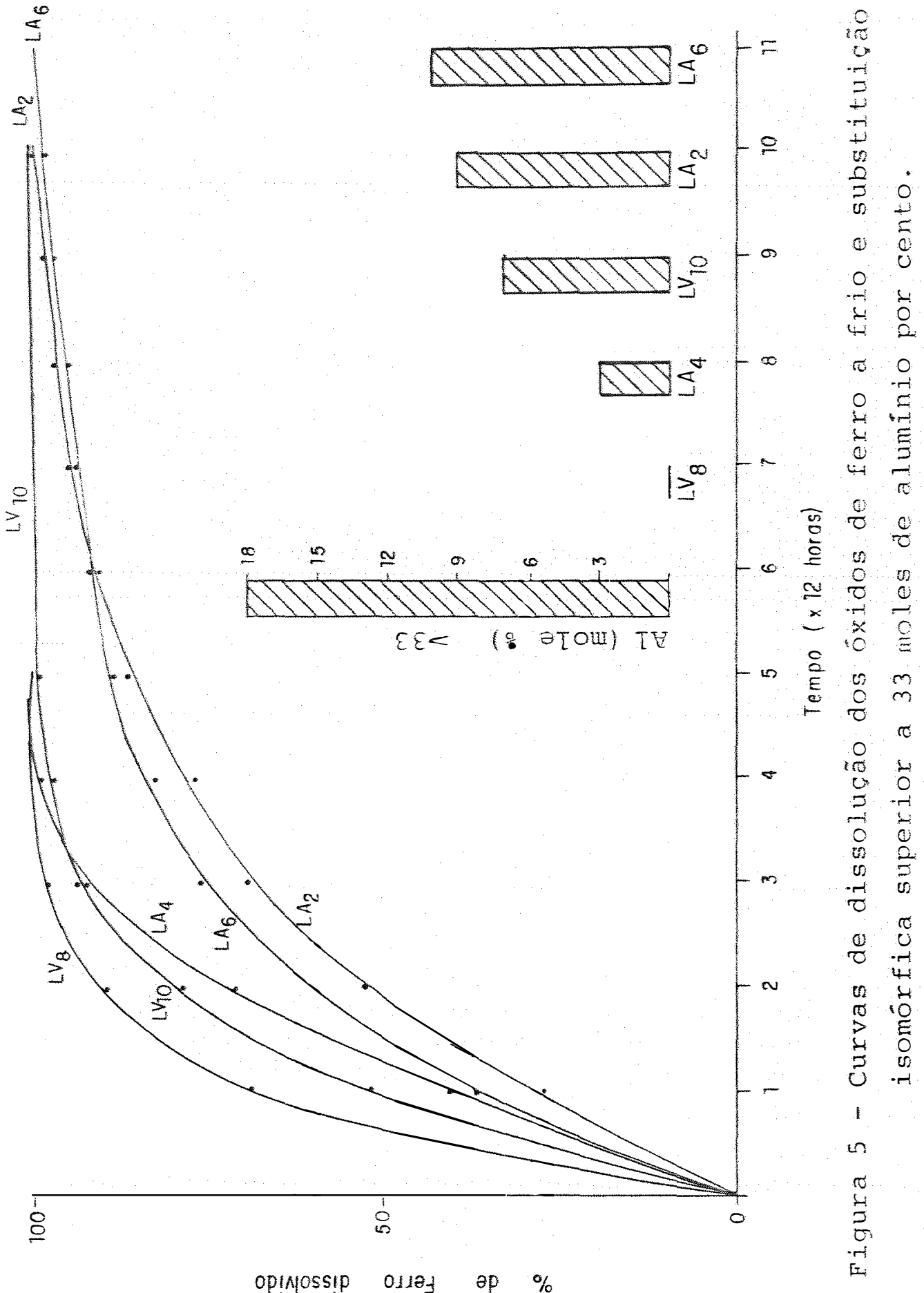


mostras (Figura 5), a sequência LV 10, LA 2 e Lî 6 é a mesma observada nas quantidades percentuais de mineral com substi tuição isomórfica superior a 33 moles por cento de alumínio, indicando claramente a influência da quantidade de óxidos al tamente aluminosos na dificuldade de redução dos mesmos.

o mineral responsável pelas altas substitui çöes isomórficas mostrou-se aqui ser a goethita, tanto pelo aspecto visual amarelado das amostras durante as extrações, como pelo fato de que este mineral nas misturas de óxidos a qui analisadas, foi o que teve maior percentagem de aluminio estrutural, conforme ficou evidenciado pelas avaliações de deslocamento dos picos de difração de raios X (Quadro 11).

Outro fator que eventualmente poderia interfe rir na velocidade de dissolução dos óxidos de ferro seria o tamanho dos cristais, muitas vezes associado na literatuta, às substituições isomórficas (SCHWERTMANN, 1984). Comparando - se a substituição média de alumínio na estrutura das goethi tas com suas dimensões cristalinas (MCD), observa-se que a $\underline{a}$ mostra LA 2, cuja MCD foi a maior de todas (102nm) apresen tou uma substituição isomórfica de 25 moles de alumínio por cento, igual à do LA 4, cuja MCD foi cerca de quatro vezes menor. Por outro lado, a amostra LV 8 onde ocorreu a menor substituição isomórfica, a MCD foi de $63 \mathrm{~nm}$, muito superior à dimensão dos cristais da amostra LV 10, com substituição iso mŕfica de 24 moles por cento; isso indica que nas goethitas estudadas não há sempre correlação entre o tamanho das partí 


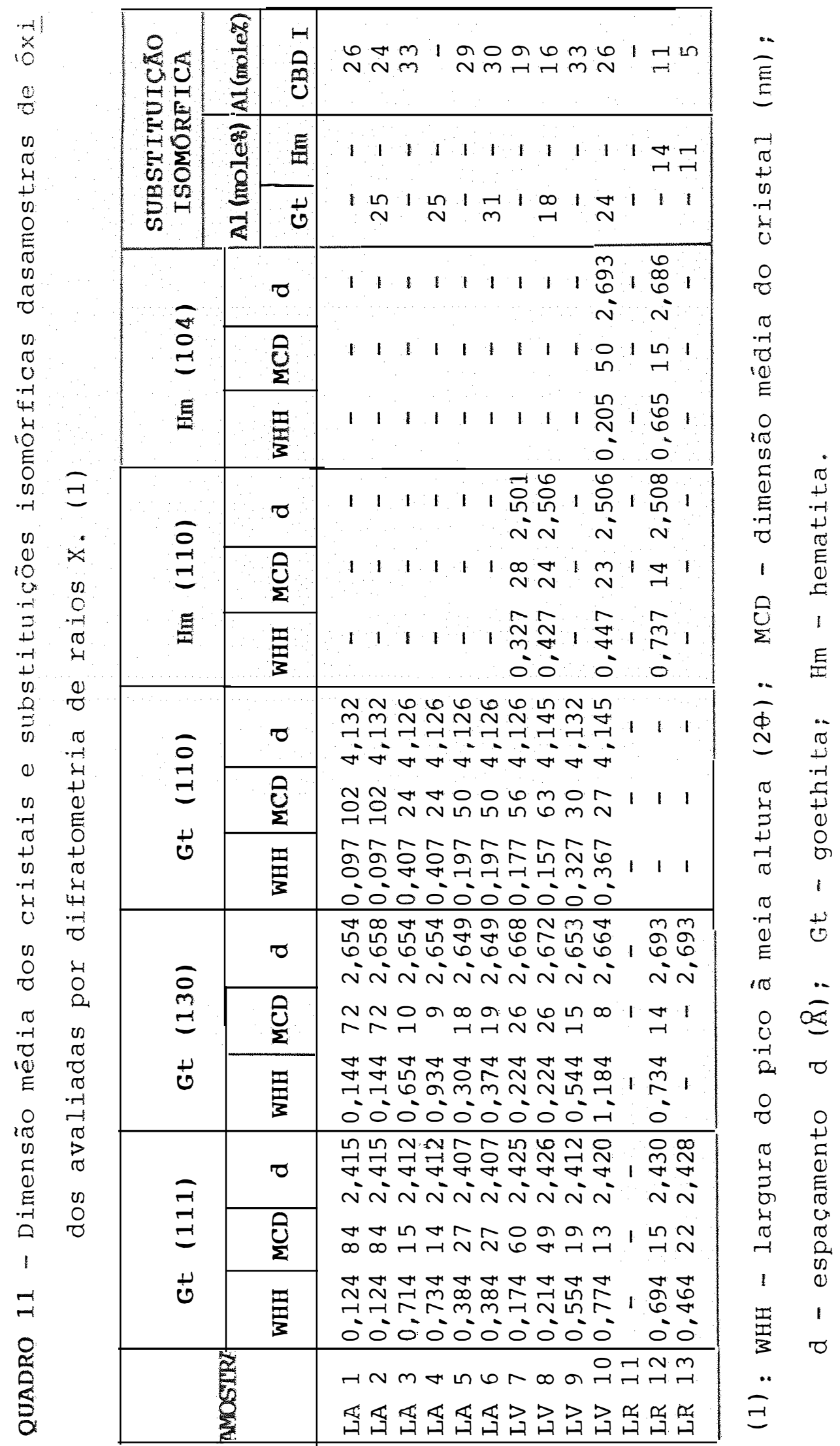


culas e a substituição isomórfica do aluminio, o que contra ria as observações de SCHWERTMANN et alii (1979) e AINSWORTH \& SUMMER (1985).

Da mesma forma, neste trabalho não foi obser vada a influēncia da substituição isomórfica de ferro pelo a luminio das goethitas na velocidade de dissolução, como ha via observado SCHWERTMANN (1984). Assim, a amostra LV 8, cuu jo tamanho médio dos cristais de goethita foi de $63 \mathrm{~nm}$, foi a que se dissolveu mais facilmente (Quadro II e Figura 5), en quanto a amostra LV 10, de dissolução bastante lenta, apre sentou goethita com MCD muito inferior, $23 \mathrm{~nm}$. Portanto, a ve locidade de dissolução das goethitas neste trabalho apareceu associada somente à quantidade de goethita com substituição isomórfica $>33 \%$ de alimínio, que não tem correlação com o tamanho das particulas.

Os resultados referentes às hematitas estão incompletos por dificuldades analiticas, quais sejam, incer teza na medida do āngulo $2 \theta$ e na largura dos picos devido a dispersão dos mesmos. Portanto não se pode fazer avaliações mais precisas deste mineral:

Há evidências de que as goethitas das amos tras LA 2 e LA 6 possam ser minerais provenientes de mate rial formado em condições diferentes daquelas usuais nos so los, portanto, sem guardar qualquer relação entre a substi tuição isomórfica e o tamanho dos cristais, enquanto as goe thitas dos outros solos poderiam ser materiais neoformados, 
nas condições normais já com uma relação entre tamanho dos cristais e a substituição isomórfica.

\subsection{Sorção de fósforo}

A seleção das amostras para os ensaios de sor ção de fósforo foi feita com base nos óxidos de ferro e na homogeneidade das caulinitas previamente analisadas.

No que se refere às caulinitas, sua desordem cristalina não implica em perfeição morfológica (RANGE et alii, 1969 e JACKSON \& ABDEL - KADER, 1978) mas aparentemen te tem grande influência no tamanho dos cristais. Os maiores tamanhos de cristais correspondem às caulinitas mais ordena das (MOLLER \& ARAKI, 1984). O fenōmeno quantitativo da sor ção depende da natureza dos sitios expostos e das suas car gas e quantidades. Os tipos de sitios são função do arranjo estrutural que expõe faces onde predominam pontos de sorção potencialmente diferentes (PARFITT, 1978), cuja carga é de pendente do $\mathrm{pH}$ e a quantidade, ao tamanho das particulas, is to é, a sua desordem cristalina.

Os resultados das análises das caulinitas dos latossolos estudados (Quadro 12) mostraram que as amostras LA 2, LA 4: e LV 8 foram as mais homogēneas entre si quanto ao tipo de caulinitas. Os indices de Hinckley, com valores de 52,50 e 51 respectivamente, e os tipos de desordem crista Iina situados nos grupos I e IV, embora em quantidades dife 


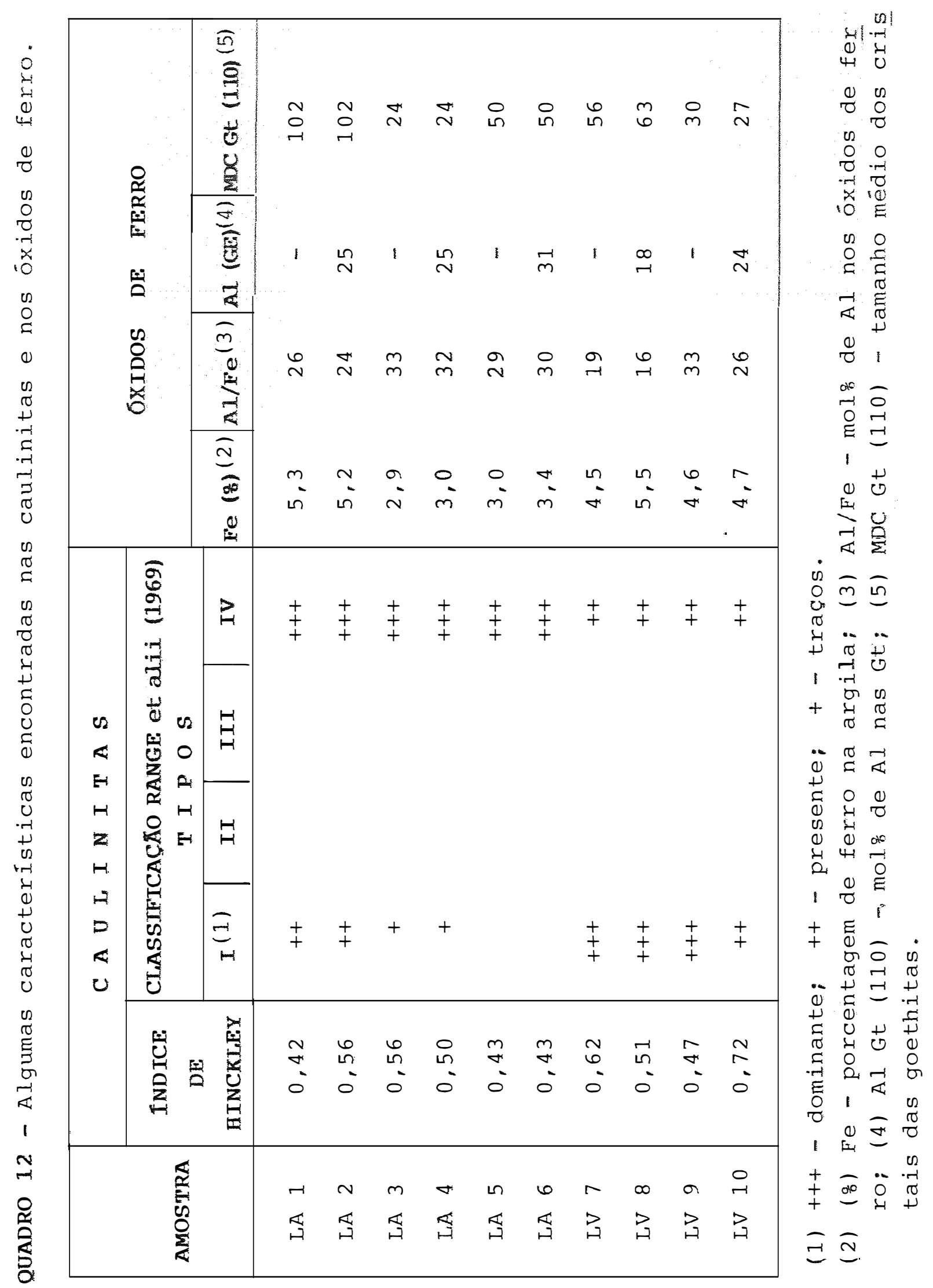


rentes, evidenciam que a influéncia da caulinita na sorção de fósforo possivelmente é semelhante para as très amsotras. Já nos óxidos de ferro das trés amostras, IA 2, LA 4 e LV 8, há nítida predomināncia de goethitas, que di ferem entre si quanto a substituição isomórfica do ferro por alumínio na mistura de óxidos (respectivamente 24,32 e 16 moles por cento), área superficial específica $(58, \quad 89$ e $68,4 \mathrm{~m}^{2} / \mathrm{g}$ respectivamente), tamanho dos cristais $(102,24$ e $63 \mathrm{~nm}$ respectivamente) e substituição isomórfica das mesmas (25, 25 e 18 moles de aluminio por cento respectivamente). Desta forma, pode-se fazer uma boa avaliação de efeito dos diferentes parāmetros das goethitas na sorção de fósforo. Le vando-se em consideração que no decorrer das reações de sor ção foram controladas no laboratório as variáveis independen tes aos minerais como sejam $\circ \mathrm{pH}$ e a relação sólido : solução e ainda que as caulinitas dentro do possivel foram mantidas bastante homogēneas nas misturas, os resultados da sorção po dem ser inferidos aos óxidos de ferro.

os resultados da sorção de fósforo obtidos nestas trés amostras (Figura 6), evidenciarammaior sorção no LA 4 muito embora esta amostra tenha somente $3 \%$ de ferro na argila, seguida da amostra LV 8 e LA 2, com teores aproxi mados de 5\% de ferro na argila. Analisando-se os resultados da sorção de fósforo e das ASE, MCD e Al da goethita, obser va-se que a ordem das amostras quanto a sorção de fósforo $($ LA $4>\operatorname{LV} 8>\operatorname{LA} 2)$ é igual a ordem quanto à superfície es 


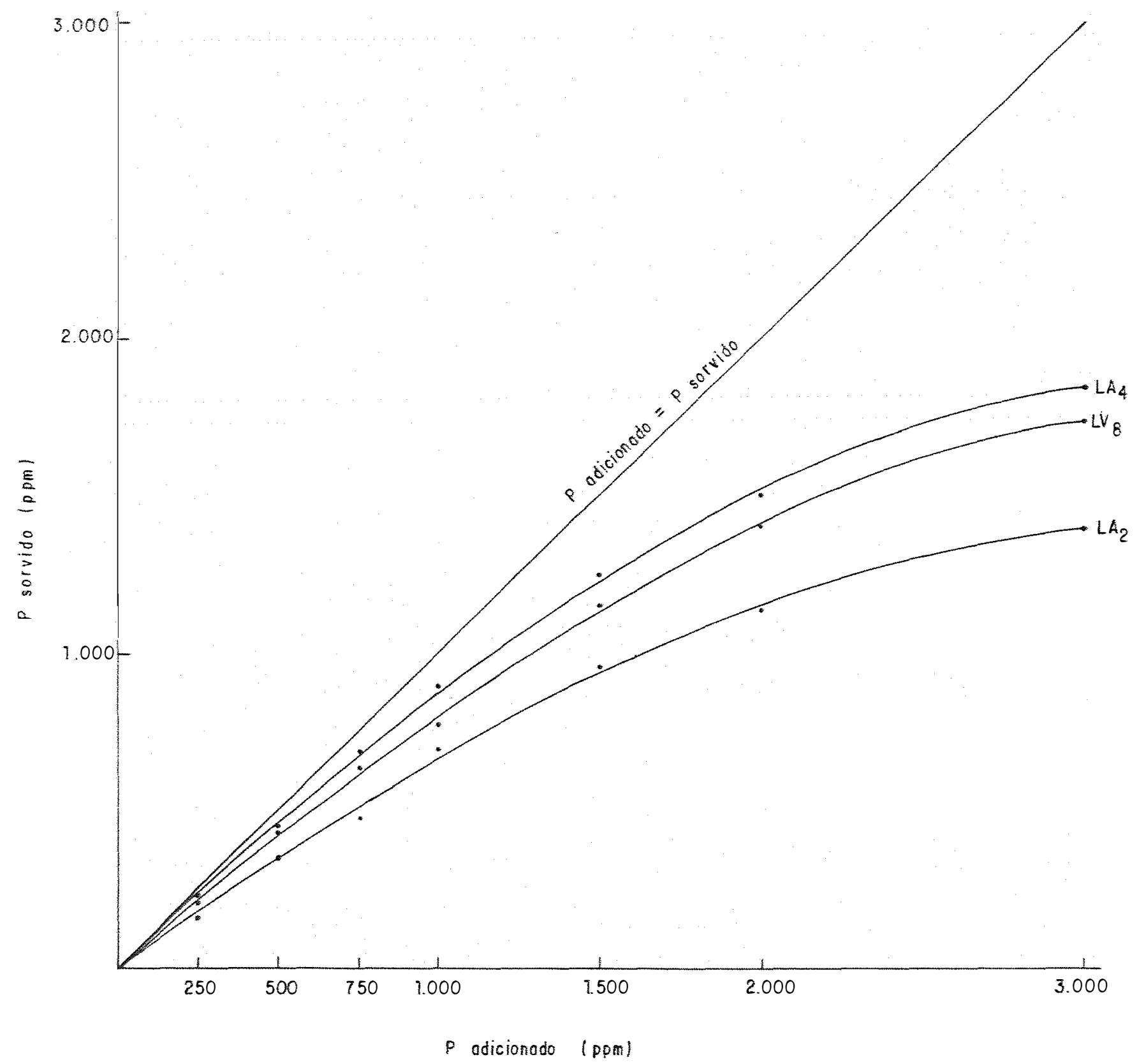

Figura 6 - Curvas de sorção de fósforo nas argilas dos solos $\mathrm{LA}_{2}$, $L^{L A_{4}}$ e $L V_{8}$. 
pecifica das goethitas das amostras (IA $4>\operatorname{LV} 8>$ LA 2) que é inversa a sequéncia da $\operatorname{MCD}($ LA $2>\operatorname{LV} 8>\operatorname{LA} 4$ ). Este fato indica que a sorção de fósforo é proporcional ao tamanho das particulas das goethitas. Já a quantidade da substituição i somórfica das amostras não apresenta qualquer correlação com a sorção de fósforo. Portanto, a reatividade dos óxidos de ferro dos solos da região deve ser avaliada pela sua ASE ou MCD, o que concorda com BORGGAARD (1983). 


\section{CONCLUSÖES}

1. Parte das goethitas dos solos estudados a presentam substituições isomórficas de aluminio superior a 33 moles por cento.

2. Não há correlação entre a substituição iso mórfica do alumínio dos óxidos e o tamanho médio dos cris tais e, consequlentemente, entre a substituição isomórfica e as superficies especificas.

3. Parte das goethitas extraidas das frações argila dos LA e LV é muito resistente ao ataque citrato-diti onito-bicarbonato devido ao alto teor de aluminio estrutural que estas contém (superior a 33 moles por cento),

4. No método MEHRA \& JACKSON (1959) há possí bilidade de interferência do aluminio dos silicatos comple xados pelo citrato de sódio, nos resultados da substituição isomórfica do ferro pelo aluminio. Modificações introduzidas no método original mostraram correlações significativas en tre os teores de Fe e Al extraídos à temperatura ambiente e a quente bem como em relação à substituição isomórfica.

5. A sorção de fósforo está correlacionada com a área superficial especifica dos minerais de ferro e 
suas MCD, enquanto a substituição isomórfica de ferro por a lumínio não mostra relação com o fenōmeno. 


\section{REFERENCIAS BIBLIOGRÁEICAS}

AINSWORTH, C.C.\& SUMMER, M.E. Effect of aluminum substitution in goethite on phosphorus adsosption. II Rate of adsorption. Soil Sci. Soc. Am. J. 49:1149-53, 1985 .

AINSWORTH, C.C.; SUMMER, M.E. \& HURST, V.J. Effect of aluminum substitution in goethite on phosphorus adsosption: I Adsosption and isotopic exchange. Soil Sci. Soc. Am. J. 49:1142-49, 1985 .

ALWIS, K.A. \& PLUTH. D:J. The red latosols of Sri Lanka: II. MIneralogy weathaering. J. Soil Sci. Soc. Am. Proc. $40(6): 920-8,1976$

BACHE, B.W. Aluminum and iron phosphate studies relating to soils. II. Reactions between phosphate and hydrons oxides. Journal of Soil Sciences, 15(1):110-6, 1964 .

BAJWA, M.I. Soil clay mineralogies in relation to fertility management; effect of soil clay mineral compositions on phosphorus fixation under conditions of wet land rice culture. Commun. in Soil Sci. Plant Anal. 12(5):475-82 1981 . 
BIGHAN, J.M.; GOLDEN, D.C.; BUOL, S.W.; WEED, S.B. \& BOWEN, L.H. Iron oxide mineralogy of weel - drained ultisols and oxisols. II Influence on color, surface area, and phosphate retention. Soil Sci. Soc. Am. J. 42:825-30, 1978.

BORGGAARD, O.K. The influence of iron oxides on phosphate adsorption by soils. Journal of Soil Sciences. 34:33-41, 1983.

BRONEVOI, V.A. \& FURMAKOVA, L.N. Formation conditions for alumino goethites in bauxites. Zap. Vses Mineral. Obshchest. 104, 461-6, 1975 (Chen. Abstr. 84, 62427).

BRYANT, R.B.; CURI, N.; ROTH, C.B. \& FRANZMEIER, D.P. Use of an internal standard with differential $\mathrm{x}$-ray difraction analysis for iron oxides. Soil Sci. Soc. Am. J. $47: 168-73,1983$.

CARSTEA, D.D. Formation and stability of Al, Fe and $\mathrm{Mg}$ interlayer in montmorillonite and vermiculite. Corvellis, U.S.A., Oregon State University, 1968. 117p. Thesis $\mathrm{Ph} . \mathrm{D}$. Soils.

CARTER, D.I.; HEILMAN, M.D.\& GONZALEZ, C.L. Ethylene glycol monoethyl ether for determining surface area of silicate minerals. Soil Sci. 100(5):356-60, 1965. 
CHAUVEL, A.; PEDRO, G. \& TESSIER, D. Rōle du fer àans I'organisation des matheriaux kaoliniques. Science du Sol, 2:101-13, 1976 .

CHIBA, M. Report on Japan-Brasil Tecnical Cooperation for the investigation of soils and fertilizers in the Amazon Region. Tokyo, OTCA, 1970. p.1-87. (In japanese).

CURI, N. \& FRANZMEIER, D.P. Toposequence of oxisols from the central plateau of Brazil. Soil Sci. Soc. An. J. $48: 311-6,1984$

DIEZ, J.A. The effect of different types of clay over dynamic of $\mathrm{P}$ in soil. Agrochimica, 24:353-60, 1980.

FEY, M.J. \& DIXON, J.B. Synthesis and properties of poorly crystaline hydrated aluminous goethites. Clays and clay Minerals, 29(2):91-100, 1981 .

FEY, M.J. \& Le ROUX, J. Propeties and quantitative estimation of poorly crystalline components in sesquioxidic soil clays. Clays and clay Minerals, $25: 285-94,1977$.

FITZPATRICK, R.W. \& SCHWERTMANN, U. AI - substituted goethite - an indicator of pedogenic and other weathering environments In South Africa. Geoderma, 27:335-47, 1982. 
GAMA, J.R.N.F. Caracterização e formação de solos com argila de atividade alta do Estado do Acre. Itagua , UFRRJ, 1986. 150p. Tese de Mestrado.

GAMA, J.R.N.F.; KUSABA, I.; OTA, T. \& AMANO, Y. Influēncia vulcānica nos solos do Estado do Acre, Amazōnia Ocidental. Rev. Bras. Ci. Solo, 1991. No prelo.

GAMA, J.R.N.F. \& MOLLER, M.R.F. Levantamento de solos na Gleba I - Tucumã - Carajás, 1982. mimeo.

GAMA, J.R.N.F. Levantamento de reconhecimento de média intensidade dos solos e avaliação da aptidão agrícola das terras da área do Polo Roraima. Rio de Janeiro, EMBRAPASNLCS, 1983. 368p. (EMBRAPA-SNLCS. Boletim de Pesquisa, 18).

GASTUCHE, M.C.; BRUGGENWENT, T. \& MORTLAND, M.M. Crystallization of mixed iron and aluminum gels. Soil Sci., 98:281-9, 1964 .

HATTORI, T.; YONEBAYASHI, K. \& KYUMA, K. Intercalation index with hydrazine, morphology and susfaces microtopography of kaolinitic clays in the tropics asian soils. Soil Sci. Plant Nutr., 25(3):425-36, 1979.

HINCKLEY, D.N. Variability in "crystallinity" values among the kaolin deposits of the coastal plain of Georgia and South Caroline. National Conference on clays and clay Minerals, 11a, 1963. p.229-35. 
IWASA, Y. Report on the Japan-Brazil Tecnical Cooperation for the investigation of soils and clay Minerals in the Amazon Region. Tokyo, JICA, 1976. p.1-117 (In Japanese).

JACKSON, M.L. Significance of kaolinite intercalation in clay mineral analysis. In: NATIONAL CONFERENCE ON CLAYS MINERALS, 9, 1962. Proceeding. New York, Pergamon, 1962. p. 424-30.

JACKSON, M.L. \& ABDEL-KADER, F.H. KaOIinite intercalation procedure for all sizes and types with $x$-ray diffraction spacing distinctive from other phyllosilicate. Clays and clay Minerals, $26(2): 81-7,1978$.

JANOT, C.: GIBERT, H.; GRAMONT, K. \& BIAIS, S. Etude des substituitions Al-Fe das les-roches lateritiques. Bull. Soc. Fr. Minéral. Cristallogr., 94:367-80, 1971.

KMMPF, N. \& SCHWERTMANN, U. The $5 \mathrm{M}$ NaOH concentration treatment for iron oxides in soils. Clays and clay Minerals, $30(6): 401-8,1982$.

KITAGAWA, Y. Goethite and hematite in some soils from the Amazon Regions. Soil Sci. Plant Nutr., 29(2):209-17, 1983. 
KITAGAWA, Y. \& MOLLER, M.R.F. Clay mineralogy of some typical soils in the brasilian Amazon region. Pesq. Agropec. Bras., Brasilia, 14(3):201-28, 1979.

KITAGAWA, Y. \& MOLLER, M.R.F. Kaolin minerals in the Amazon soils. Soil Sci. Plant. Nutr., 26:255-69, 1980.

KITTRICK, J.A. Soil minerals in the $\mathrm{Al}_{2} \mathrm{O}_{3}-\mathrm{SiO}_{2}-\mathrm{H}_{2} \mathrm{O}$ system and theory of their formation. Clays and clay Minerals, $17: 157-67,1969$.

KLUG, H.P. \& ALEXANDER, L.E. X ray diffraction procedure for polycrystalline and amorphous materials. New York, Wiley, 1974. 966p.

MEHRA, O.P. \& JACKSON, M.L. Iron oxide removal from soil and clays by a dithionit-citrate-system buffered with sodium bicarbonate. Clays and clay Minerals, 7:317-27, 1959 .

MENDELOVICI, E.; YARIV, Sh. \& VILLALBA, R. Aluminum-bearing goethite in Venezuelan laterites. Clays and clay Minerals, 27:368-72, 1979 .

MOLLER, M.R.F. \& ARAKI, S. Intercalação de caulinitas separadas de latossolos. Belém, EMBRAPA-CPATU, 1984. 20p. (EMBRAPA-CPATU, Boletim de Pesquisa, 61). 
MOLLER, M.R.F. \& KITAGAWA, Y. Mineralogia de argila em cambissolos do sudoeste da Amazônia brasileira. Belém, EMBRAPA-CPATU, 1982. 19p. (EMBRAPA-CPATU. Boletim de Pesquisa, 34).

MOLLER, M.R.F. \& KLAMT, E. Sorção de fósforo por colóides inorgânicos extraídos de dois solos da Amazōnia. Belém, EMBRAPA-CPATU, 1984. 16p. (EMBRAPA-CPATU. Boletim de Pesquisa, 60).

NORRISH, K. \& TAYLOR, R.M. The isomorphous replacement of iron by aluminum in soil goethites. Journal of Soils Sciences, 12(2):294-306, 1961 .

PAREITT, R.L. Anion adsorption by soils and soil materials. Adv. in. Agron., 30:1-50, 1978.

RANGE, K.J.; RANGE, A. \& WEISS, A. Fire clay type kaolinite or fire clay minerals? Experimental classification of kaolinite and halloysite minerals. Int. clay conf., 4th, 1969. Proceedings. p.3-13.

REGO, R.S. \& SOARES, A.F. et alii. Levantamento de reconhecimento de média intensidade e aptiđão agrícola dos solos ea área do Polo Altamira, PA. Rio de Janeiro, EMBRAPA-SNLCS, 1981. 183p. (EMBRAPA-SNLCS. Boletim de Pesquisa, 77) . 
REGO, R.S. \& SOARES, A.F. et alii. Levantamento de reconhecimento de média intensidade dos solos e avaliação da aptidão agrícola das terras da área do Polo PréAmazônia maranhense. Rio de Janeiro, EMBRAPA-SNLCS, 1982. 290p. (EMBRAPA-SNLCS. Boletim de Pesquisa, 15).

REGO, R.S. \& IIMA, A.A.C. et alii. Levantamento de reconhecimento dos solos e avaliação da aptidão agrícola das terras da área do Polo Carajás, Estado do Pará. Rio de Janeiro, EMBRAPA-SNLCS, 1984. 120p. (EMBRAPA-SNLCS. Boletim de Pesquisa, 29).

SANTOS, P.L. dos et alii. Levantamento de reconhecimento de média intensidade dos solos e avaliação da aptidão agrícola das terras da área do Polo Amapá. Rio de Janeiro, EMBRAPA-SNLCS, 1982. 405p. (EMBRAPA-SNLCS. Boletim de Pesquisa, 3).

SCHUlzE, D.G. The influence of aluminum on iron oxides. VIII Unit-cell adimentions of Al-substitutied goethites and estimation of Al from them. Clays and clay Minerals, $32(1): 36-44,1984$

SCHWERTMANN, U. The influence of aluminum on iron oxides: IX Dissolution of Al-goethites in $6 \mathrm{M} \mathrm{HCl.} \mathrm{Clay} \mathrm{Minerals,}$ 19:9-19, 1984 . 
SCHWERTMANN, U. \& TAYLOR, R.M. IrOn oxides. In: DIXON, J. B. ed. Minerals in Soil Environments. Madison, Soil Science Society of America, 1977. p.145-80.

SCHWERTMANN, U.; FITZPATRICK, R.W. \& Le ROUX, J.AI substitution and differential disorder in soil hematites. Clays and clay Minerals, 25:373-4, 1977.

SCHWERTMANN, U.; FITZPATRICK, R.W.; TAYLOR, R.M. \& LEWIS, D.G. The influence of aluminum on iron oxides Part II. Preparation and properties of Al substituted hematites. Clays and clay Minerals, 27(2):105-12, 1979.

SCHWERTMANN, U. Occurrence and formation of iron oxides in various pedoenvironments. In: STUCKI, J.W.; GOADMAN, A. \& SCHWERTMANN, U. ed. Iron in soils and clay minerals. Bad Windsheim, NATO, 1985. p.758-812.

SING, R.; MOLLER, M.R.F. \& FERREIRA, W. Características da sorção de fósforo relacionadas com propriedades selecionadas dos solos dos trópicos úmidos da Amazōnia. R. bras. Ci. Solo, 7:233-41, 1983 .

TANNER, G.B. \& JACKSON, M.L. Nomographs of sedimentation times for soil particle under gravity or centrifugal aceleration. Soil Sci. Soc. Am. Proc., 12:60-5, 1947. 
TOWSEND, F.C. \& READ, L.W. Effects of amorphous constituents on some mineralogical and chemical properties of a panamanian latosol. Clays and clay Minerals, 19:303-10, 1971 .

UEHARA, G. \& GILLMAN, G. The mineralogy, chemistry, and physics of tropical soils with variable charge clays. Bouldeiwest new, 1981. 170p. (Westview Tropical Agriculture Sere, 41 . 
A $\mathbf{N} \times$ O 
ANEXO 1 - Valores fornecidos pelo step scaning.
A M O S T R A
I A 2

\begin{tabular}{|c|c|c|c|c|c|c|}
\hline \multirow[b]{2}{*}{$\begin{array}{c}\text { Intervalo } \\
2 \theta\end{array}$} & \multicolumn{2}{|c|}{ Difração } & \multirow[b]{2}{*}{$\begin{array}{c}\text { Largura } \\
2 \theta\end{array}$} & \multirow[b]{2}{*}{ Cauchy } & \multirow[b]{2}{*}{$\begin{array}{c}\text { Linha de base } \\
2 \theta\end{array}$} & \multirow[b]{2}{*}{$\begin{array}{l}\text { C.V. } \\
\frac{8}{8}\end{array}$} \\
\hline & $\begin{array}{l}\text { Inpulso } \\
\text { cps }\end{array}$ & $\begin{array}{c}\text { Posição } \\
2 \theta\end{array}$ & & & & \\
\hline $20-22$ & 3.145 & 20,969 & 0,257 & 0,700 & $1.506-1.534$ & 4,792 \\
\hline \multirow[t]{2}{*}{$22-27$} & 5.052 & 24,825 & 0,304 & 0,616 & $1.568-1.652$ & 4,841 \\
\hline & 25.741 & 24,959 & 0,197 & & & \\
\hline \multirow[t]{3}{*}{$27-32,5$} & 10.802 & 29,441 & 0,207 & & $1.535-1.726$ & 5,533 \\
\hline & 4.448 & 31,030 & 0,220 & 0,666 & & \\
\hline & 1.110 & 31,974 & 0,297 & & & \\
\hline $32,5-35$ & 11. 360 & 33,149 & 0,187 & 0,796 & $1.409-1.552$ & 5,897 \\
\hline \multirow[t]{2}{*}{$35-40$} & 960 & 33,914 & 0,973 & 0,579 & $1.391-1.511$ & 3,690 \\
\hline & 8.546 & 39,308 & 0,273 & & & \\
\hline \multirow[t]{5}{*}{$40-44,5$} & 2.532 & 41,120 & 0,364 & & $776-1.549$ & 3,676 \\
\hline & 2.262 & 42,039 & 0,453 & & & \\
\hline & 3.039 & 42,758 & 0,288 & 0,782 & & \\
\hline & 15.306 & 43,412 & 0,340 & & & \\
\hline & 2.278 & 44,199 & 0,268 & & & \\
\hline $44,5-45,5$ & 586 & 45,065 & 0,238 & 0,832 & $1.341-1.531$ & 4,230 \\
\hline \multirow[t]{4}{*}{$45,5-50,5$} & 5.359 & 47,433 & 0,348 & 0,640 & $1.159-1.364$ & 3,821 \\
\hline & 6.413 & 48,901 & 0,306 & & & \\
\hline & 776 & 49,352 & 0,623 & & & \\
\hline & 517 & 49,736 & 0,141 & & & \\
\hline \multirow[t]{3}{*}{$50,5-54,5$} & 279 & 51,210 & 0,489 & 0,736 & $1.205-1.181$ & 4,641 \\
\hline & 220 & 52,262 & 0,159 & & & \\
\hline & 685 & 53,603 & 0,357 & & & \\
\hline \multirow[t]{3}{*}{$54,5-57,5$} & 4.896 & 55,544 & 0,263 & 0,659 & $1.224-1.176$ & 6,136 \\
\hline & 1.700 & 55,660 & 0,241 & & & \\
\hline & 3.654 & 56,372 & 0,307 & & & \\
\hline
\end{tabular}


ANEXO 2 - Valores corrigidos pelo padrão de silica.

$$
\text { A M O S T R A L I A } 2
$$

\begin{tabular}{|c|c|c|c|c|c|c|c|}
\hline aservad & $\begin{array}{l}2 \theta \\
\text { Corrigido }\end{array}$ & $d$ & cps & WHE & LB & C.V. & $\begin{array}{c}\text { Intervalo } \\
2 \theta\end{array}$ \\
\hline 20,969 & 20,995 & 4,9130 & 3.182 & 0,251 & $1.528-1.508$ & 4,71 & $20-22,5$ \\
\hline 23,160 & 23,188 & 4,4539 & 186 & 0,319 & $1.211-1.608$ & 9,69 & $22,5-26$ \\
\hline 24,299 & 24,328 & 4,2481 & 646 & 0,2 & $1.211-1.608$ & 9,69 & $22,5-26$ \\
\hline 4,945 & 24,975 & 4,1399 & 3.614 & 0,226 & $1.211-1.608$ & 9,69 & 22 \\
\hline, 242 & 29,2 & 3,5424 & 189 &, 366 & $1.405-1.587$ & 5,87 & $26-30,5$ \\
\hline, 441 & 29,473 & 3 & 10.765 & 0,209 & $1.405-1.587$ & 5,82 & $26-$ \\
\hline 1,030 & 31,062 & 3,3430 & 4.511 & 0,215 & $1.405-1.613$ & 5,18 & $30,5-35$ \\
\hline 5.8 & 1 & & 9 & & & 5,18 & \\
\hline 9 & 0, & 0 & 1.3 & 0 , & $5-1$ & 5,18 & 3 \\
\hline, 301 & 39, & 2,65 & 8.977 & 0,282 & $1.635-1.492$ & 8,81 & -40 \\
\hline, 120 & 41, & & 2.5 & , & $100+$ & 3,68 & 20 \\
\hline, 039 & 42,072 & 2,4937 & 2.267 & 0,455 & $760-1.547$ & 3,68 & $40-44,5$ \\
\hline, 758 & 42, & & 3.0 & & & 3,68 &, 5 \\
\hline 3,412 & 43,4 & 36 & 15.3 & 0, & $0-1 \cdot 5$ & 3,68 & $40-$ \\
\hline 200 & 44,232 & 2,3776 & .290 & 0 , & 5 & 3,68 & $40-$ \\
\hline, 053 & $45, c$ & & 568 & & & 3,92 &, 5 \\
\hline, 596 & 46,628 & 2 , & 5 & 0, & $7-1$ & 3,92 & $44,5-50,5$ \\
\hline, 433 & 47, & & 7 & & & 3,92 & \\
\hline 48,352 & 48,385 & 2,1843 & 768 & 0, & $1.157-1.434$ & 3,92 & $44,5-50,5$ \\
\hline, 901 & 48,933 & & 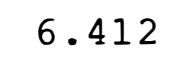 & & $1.157-1.434$ & 3,92 & $44,5-50,5$ \\
\hline 49,725 & 49,757 & 2 , & 565 & 0, & 34 & 3,92 & $-50,5$ \\
\hline 51,199 & 51,231 & 2,0705 & 285 & 0,467 & $1.183-1.204$ & 4,62 & $50,5-54,5$ \\
\hline, 2 & 5 & & 218 & 0,162 & $1.183-1.204$ & 4,62 & $50,5-54,5$ \\
\hline 53,603 & 53,635 & 1,9 & 683 & 0,3 & $1.183-1.204$ & 4,62 & $50,5-54,5$ \\
\hline 55,510 & 0,022 & 0,0000 & 3.102 & 0,189 & $1.210-1.204$ & 5,14 & $54,5-57,5$ \\
\hline 55,620 & 0,043 & 0,0000 & 2.076 & 0,2 & $1.210-1.204$ & 5,14 & $54,5-57,5$ \\
\hline 56,373 & 56,405 & & 3.693 & 0,306 & $1.210-1.204$ & 5,14 & $54,5-57,5$ \\
\hline 56,722 & 56,754 & 1,8834 & 53 & 0,735 & $1.210-1.204$ & 5,14 & $54,5-57,5$ \\
\hline
\end{tabular}


An 3 - Difratograma do pico Gt (110), da amostra LA ${ }_{2}$.

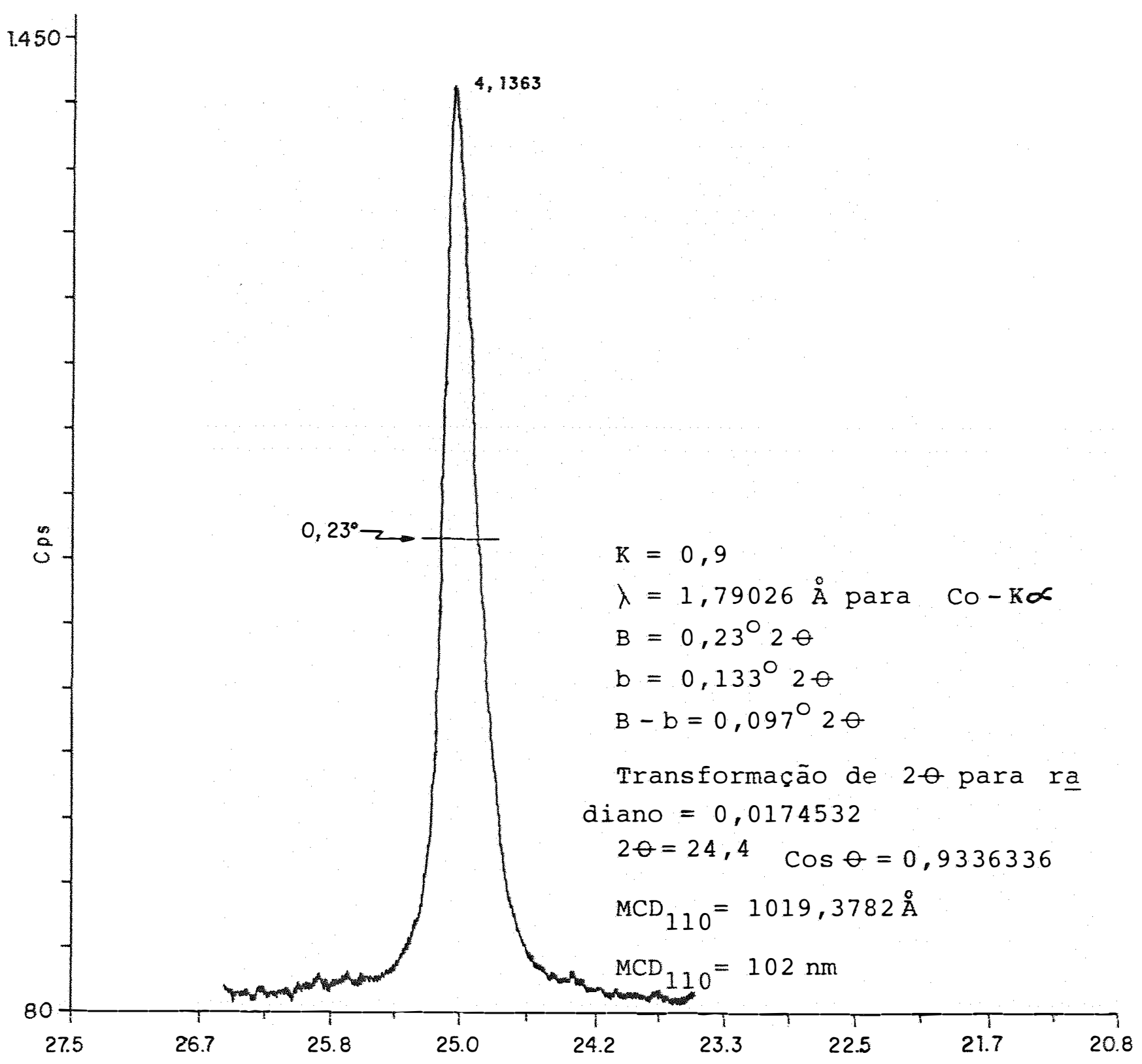




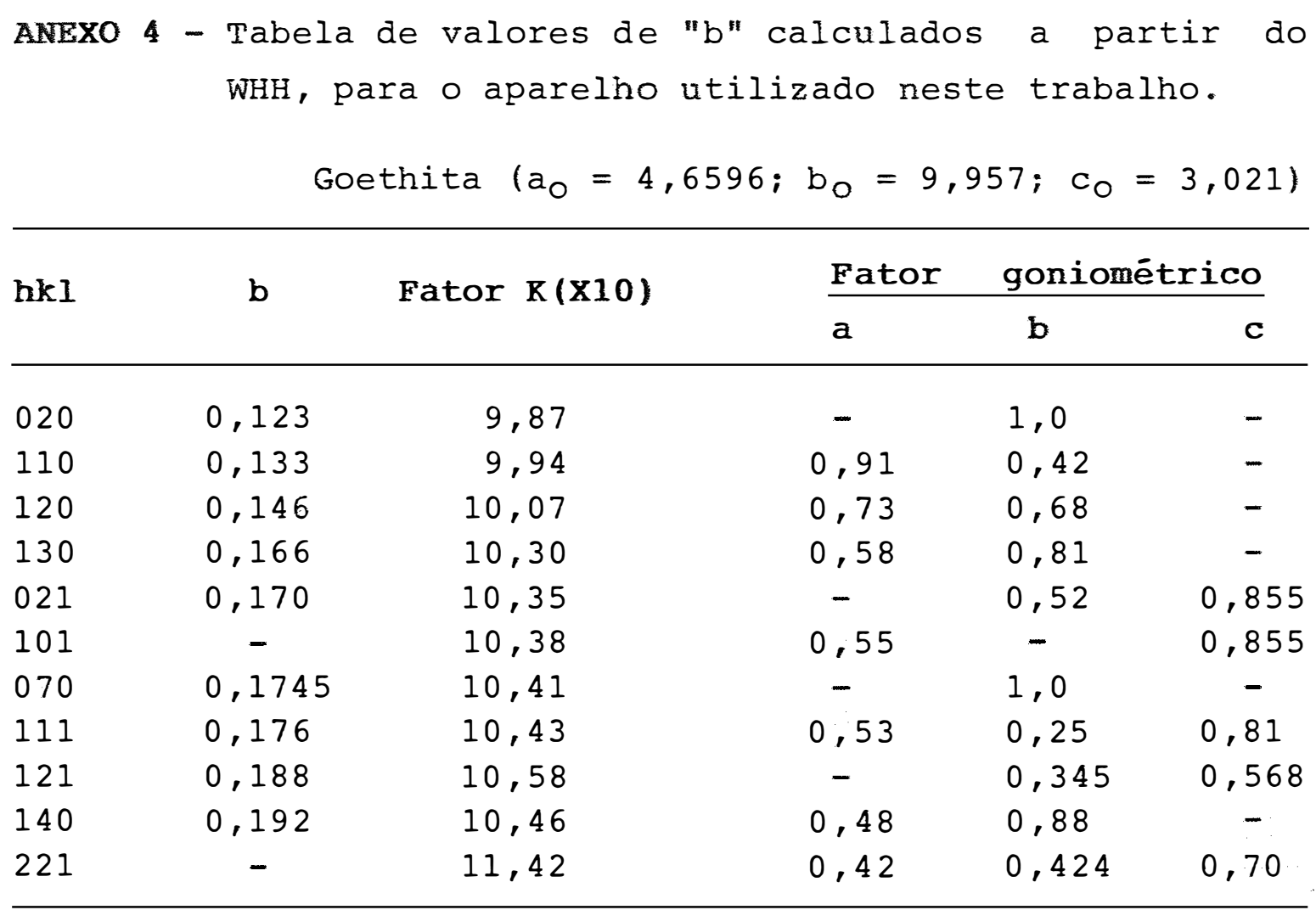

Hematita $\left(a_{0}=5,04 ; c_{0}=13,77\right)$

\begin{tabular}{|c|c|c|c|c|}
\hline \multirow{2}{*}{$\mathbf{h k l}$} & \multirow{2}{*}{ b } & \multirow{2}{*}{ Fator $\mathrm{K}(\mathrm{X} 10)$} & \multirow{2}{*}{$\frac{\text { Fator }}{a}$} & \multirow{2}{*}{$\frac{\text { goniométrico }}{c}$} \\
\hline & & & & \\
\hline 012 & 0,140 & 10,01 & 0,42 & 0,535 \\
\hline 104 & 0,165 & 10,30 & 0,62 & 0,785 \\
\hline 110 & 1,173 & 10,39 & 0,87 & - \\
\hline 113 & 0,190 & 10,62 & 0,76 & 0,48 \\
\hline 024 & 0,222 & 11,11 & 0,42 & 0,535 \\
\hline 116 & 0,240 & 11,44 & 0,58 & 0,74 \\
\hline 018 & 0,255 & 11,41 & 0,184 & 0,93 \\
\hline 214 & 0,276 & 12,16 & 0,85 & 0,43 \\
\hline 300 & 0,284 & 12,32 & 1,0 & - \\
\hline 119 & 0,324 & 13,32 & 0,45 & 0,855 \\
\hline 220 & 0,338 & 13,80 & 0,87 & - \\
\hline 128 & 0,371 & 14,73 & 0,55 & 0,69 \\
\hline
\end{tabular}


ANEXO 5 - Cálculo da substituição isomórfica do alumínio nas goethitas.

Amostra LA 2 - goethita

Sistema cristalográfico - ortorombico

Medidas dos cristais

$$
\begin{aligned}
& a-4,56265 \AA \pm 0,00223 \\
& b-9,81624 \AA \pm 0,00160 \\
& c-2,98077 \AA \pm 0,00059
\end{aligned}
$$

volume - $133,5028 \AA^{3}$

$$
\begin{aligned}
& \text { (hkl) d ( } \\
& 020 \quad 4,90812 \\
& 110 \quad 4,13754 \quad d^{2}=17,119237 . \ddots \frac{1}{d^{2}}=0,0584138 \\
& 120 \quad 3,34175 \\
& 130 \quad 2,65900 \\
& 021 \quad 2,54773 \\
& 040 \quad 2,45406 \\
& 111 \quad 2,41851 \quad d^{2}=5,8491906 . \therefore \frac{1}{d^{2}}=0,1709638 \\
& 121 \quad 2,22444 \\
& 140 \quad 2,16127 \\
& 131 \quad 1,98424 \\
& c=[(0,1709638)-(0,0584138)]^{-\frac{1}{2}} \therefore c=2,9807617 \\
& \text { mol Al\% }=1730-572 \mathrm{c} \\
& \operatorname{mol} \text { Alo }=25,004335=25
\end{aligned}
$$

